\title{
Slurry Pump Mixing Effectiveness in Tank 50H
}

\author{
Si Young Lee and Richard A. Dimenna
}

February 2008

Washington Savannah River Company Savannah River National Laboratory Aiken, SC 29808 


\section{DISCLAIMER}

This report was prepared by Washington Savannah River Company (WSRC) for the United States Department of Energy under Contract No. DE-AC09-96SR18500 and is an account of work performed under that contract. Neither the United States Department of Energy, nor WSRC, nor any of their employees makes any warranty, expressed or implied, or assumes any legal liability or responsibility for the accuracy, completeness, or usefulness, of any information, apparatus, or product or process disclosed herein or represents that its use will not infringe privately owned rights. Reference herein to any specific commercial product, process, or service by trademark, name, manufacturer or otherwise does not necessarily constitute or imply endorsement, recommendation, or favoring of same by WSRC or by the United States Government or any agency thereof. The views and opinions of the authors expressed herein do not necessarily state or reflect those of the United States Government or any agency thereof.

\section{Printed in the United States of America}

Prepared For

U.S. Department of Energy 
Keywords: CFD Calculations,

Sludge Mixing Analysis, Tank 50H,

Flow Patterns, Standard Slurry Pump

\title{
Slurry Pump Mixing Effectiveness in Tank 50H
}

\author{
Si Young Lee and Richard A. Dimenna
}

February 2008

Washington Savannah River Company Savannah River National Laboratory Aiken, SC 29808

Prepared for the U.S. Department of Energy Under Contract No. DE-AC09-96SR18500

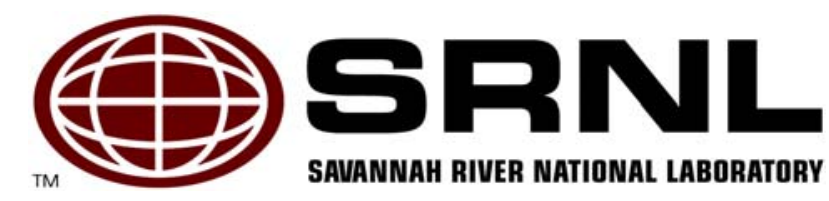




\section{Review and Approvals}

S. Y. Lee, Author

Date

Eng. Modeling and Simulation Group, SRNL

R. A. DTmenna, Coauthor

Date

Eng. Modeling and Simulation Group, SRNL

M. R. Duignan, Technical Reviewer

Date

Process Enaineerina Dev.. SRNL

I. E. Britt, Customer Reviewer

Date

Liquid Waste Organization

S. J. Herisel, Manager

Date

Eng. Modeling and Simulation Group, SRNL. 


\section{Table of Contents}

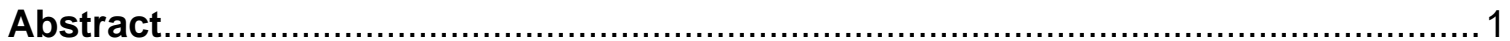

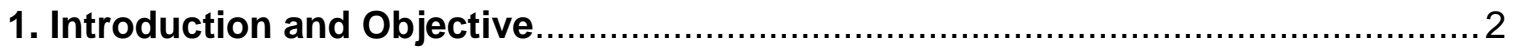

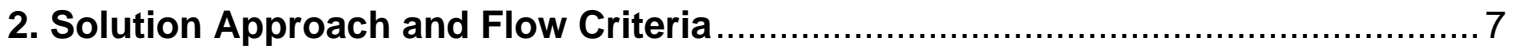

2.1 Estimation of Minimum Suspension Velocity During Jet mixing ........................ 8

2.2 Settling Velocity for Mono-sized Particles in Stagnant Fluid ............................ 10

2.3 Mixing Criterion for Sludge Particles in Tank 50H ...................................... 14

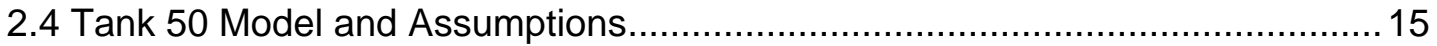

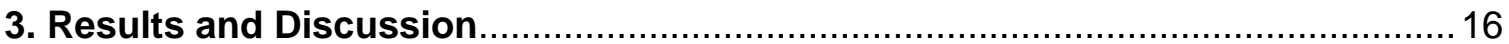

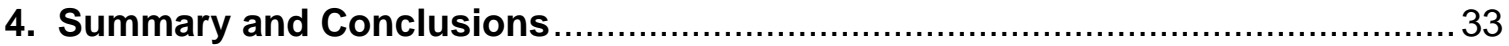

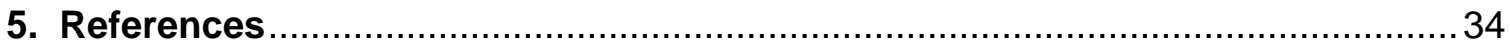




\section{List of Figures}

Figure 1. Geometrical configurations [2] and three-dimensional modeling domain containing three SSPs and one transfer pump in the analysis of the Tank 50

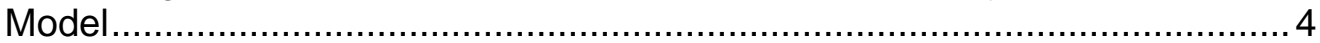

Figure 2. Three different sensitivity cases under the Case-2 study .............................. 5

Figure 3. Pump locations for the two SSPs of the Case-3 study .................................. 6

Figure 4. Pump location for the one SSP of the Case-4 study .................................. 6

Figure 5. Minimum velocity required to suspend particle from the floor ......................... 9

Figure 6. Velocity criteria for deposition, scouring, and erosion of sludge solids for the present operating conditions ................................................................... 10

Figure 7. Particle settling velocity as function of particle sizes for different solid contents in a slurry of 2.5 spg solids.................................................................... 14

Figure 8. Transient velocity magnitude around the inlet region of TTP (Riser B5) under the baseline pump orientations of Case-2a (See Fig. 9 for flow patterns at points $A, B$, and $C$.)

Figure 9. Pump nozzle orientations for three locations of Fig. 6 at the nozzle discharge plane in Tank 50, showing the red color representing local velocity magnitude

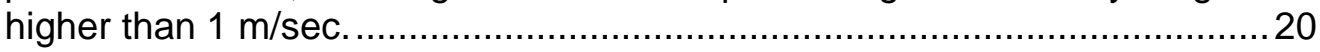

Figure 10. Turbulent intensity around the inlet region of TTP (Riser B5) .....................2 21

Figure 11. Turbulent energy dissipation rate around the inlet region of TTP (Riser B5) 21

Figure 12. Turbulent eddy viscosity around the inlet region of TTP (Riser B5)..............22

Figure 13. Velocity magnitude at the vertical and horizontal planes crossing the inlet region of the transfer pump TTP (Riser B5) at transient time 240 seconds, showing that red zone has local velocity magnitude higher than $0.07 \mathrm{~m} / \mathrm{sec} 22$

Figure 14. Velocity magnitude at the vertical and horizontal planes crossing the inlet region of the transfer pump TTP (Riser B5) at transient time 275 seconds .. 23

Figure 15. Velocity magnitude at the vertical and horizontal planes crossing the inlet region of the transfer pump TTP (Riser B5) at transient time 300 seconds showing that red zone has local velocity magnitude higher than $0.07 \mathrm{~m} / \mathrm{sec} 23$

Figure 16. Transient snapshots of turbulent intensity and eddy viscosity at the horizontal plane crossing the inlet region of the transfer pump TTP (Riser B5) at transient time 300 seconds 24

Figure 17. Comparison of transient velocity magnitude around the inlet region of TTP (Riser B5) between synchronous and asynchronous rotational speeds of B2 pump. 25

Figure 18. Comparison of transient velocity magnitudes around the inlet region of TTP (Riser B5) between asynchronous and random initial conditions of B2 pump. 
WSRC-STI-2008-00151

Figure 19. Comparison of transient velocity magnitudes around the inlet region of TTP (Riser B5) between the two different operating conditions of three SSPS (Case-2a) and two SSPs (Case-3).

Figure 20. Comparison of transient turbulent eddies around the inlet region of TTP (Riser B5) between three and two SSPs operations

Figure 21. Velocity magnitude at the vertical and horizontal planes crossing the inlet region of the transfer pump TTP (Riser B5) at transient time 300 seconds under the Case-3 operating condition, showing that red zone has local velocity magnitude higher than $0.07 \mathrm{~m} / \mathrm{sec}$ 28

Figure 22. Velocity magnitude at the vertical and horizontal planes crossing the inlet region of the transfer pump TTP (Riser B5) at transient time 300 seconds under the Case-4 operating condition, showing that red zone has local velocity magnitude higher than $0.07 \mathrm{~m} / \mathrm{sec}$ 28

Figure 23. Comparison of quasi-steady snapshots of flow velocity magnitudes at the horizontal plane crossing the inlet region of the transfer pump TTP (Riser B5) (Red zone has local value higher than $0.07 \mathrm{~m} / \mathrm{sec}$.)

Figure 24. Comparison of transient velocity magnitudes at the inlet region of the transfer pump TTP (Riser B5) under various pump combinations as shown in Table 1

Figure 25. Comparison of quasi-steady snapshots of turbulent eddy viscosity at the horizontal plane crossing the inlet region of the transfer pump TTP (Riser B5) (Red zone has local value higher than $1 \mathrm{~kg} / \mathrm{m}-\mathrm{sec}$.)

Figure 26. Comparison of quasi-steady turbulent eddy viscosities at the horizontal plane crossing the inlet region of the transfer pump TTP (Riser B5) under various pump combinations as shown in Table 1 


\section{List of Tables}

Table 1. Comparison of pump design parameters between quad volute and standard slurry pumps [1]

Table 2. Four different combinations of operating pump configurations in Tank $50 \ldots \ldots .3$

Table 3. Literature correlations for relative settling velocities based on solid volume fraction (relative settling velocity $V_{r}$ is defined by Eq. (12)).

Table 4. Settling velocity and average settling times for different sludge particle sizes in slurries containing two different solid contents $\left(\rho_{f}=1.0 \mathrm{gm} / \mathrm{cc}, \rho_{\mathrm{s}}=2.5 \mathrm{sg}\right) \ldots 13$

Table 5. Summary of local flow velocity magnitude and flow mixing time to establish quasi-steady flow patterns under various cases 


\section{Abstract}

Computational Fluid Dynamics (CFD) models of Tank 50 with different numbers of pumps and operational modes, including pump rotation, have been developed to estimate flow patterns and the resultant sludge mixing. Major solid obstructions including the tank wall, the pump housing, the pump columns, and the 82-in central support column were included in the model.

Transient analyses with a two-equation turbulence model were performed with FLUENT $^{\mathrm{TM}}$, a commercial CFD code. All analyses were based on three-dimensional results. Recommended operational guidance was developed assuming that local fluid velocity and characteristic measures of local turbulence could be used as indicators of sludge suspension and spatial mixing.

The calculation results show that three pumps, the maximum number of pumps studied, will give acceptable homogeneous mixing in about 6 minutes in terms of flow patterns and turbulent energy dissipation. These qualitative results are consistent with literature results. Sensitivity calculations have also been performed to assess the impact of different operating modes on sludge suspension and mixing. Two-pump operation provides a marginal level of sludge suspension and turbulent mixing, while one pump does not provide acceptable flow patterns and turbulent eddies for good mixing. 


\section{Introduction and Objective}

Tank $50 \mathrm{H}$ is a mixing tank to feed slurry to the Saltstone facility, which requires a homogeneous slurry feed. The work scope described here included four basic cases, all of which dealt with a particular pump configuration using a combination of pump type and number of pumps $(3,2$, or 1 operating pumps), the resulting flow pattern from that configuration, and the impact of the flow pattern on particle distribution in Tank 50. The common question for all the configurations was the state of solids distributions in the tank region supplying flow to the transfer pump.

The primary objective of the computational modeling work is to assess the impact of different pump combinations on sludge solids suspension and mixing in Tank $50 \mathrm{H}$ [1]. For this work, four different combinations of a maximum of three pumps are considered to determine the resulting flow patterns and turbulent eddies related to the turbulent kinetic energy dissipation and flow parameters which are thought to be associated with sludge particle suspension and mixing. Two different types of pumps are used for an assessment of the impact of different pump combinations on the tank mixing. They are quad volute pump (QVP) and standard slurry pumps (SSP). Their design and operating parameters are summarized and compared in Table 1.

For the first two cases, Case-1 and Case-2, three pumps are used to mix the tank, either one QVP and two SSPs or three SSPs. Case-3 considered two operating pumps, while Case-4 simulated operation with a single standard slurry pump as the worst scenario. All the cases studied here are provided in Table 2. As shown in the table, Case-2 is taken as the baseline modeling conditions, since the product $d_{0} U_{o}$ for the QVP is about twice that of the SSP as shown in Table 1. Thus, if Case-2 has sufficient flow to suspend and mix the solids, Case-1 will satisfy the flow mixing requirement. It will use three SSPs to mix the tank sludge. Locations for the three pumps of Case-2 are shown in Fig. 1. Each pump rotates counterclockwise under a range of different operating modes (such as asynchronous rotation speed) and nozzle orientations. Figure 2 shows detailed pump orientations considered for the sensitivity studies of asynchronous and orientation cases under Case-2. Pump positions and initial orientations for Case-3 and Case-4 are shown in Figs. 3 and 4, respectively. 
Page: 3 of 34

Table 1. Comparison of pump design parameters between quad volute and standard slurry pumps [1]

\begin{tabular}{|c|c|c|}
\hline Pumps & $\begin{array}{c}\text { Quad volute pump } \\
\text { (QVP) }\end{array}$ & $\begin{array}{c}\text { Standard slurry pump } \\
\text { (SSP)* }\end{array}$ \\
\hline Power, hp & 300 & 150 \\
\hline Number of nozzles & 2 & 1200 (2 nozzles) \\
\hline Flow rate per nozzle, gpm & 5200 (2 nozzles) & 1.5 \\
\hline Nozzle diameter, inches & 3.625 & 0.2 \\
\hline $\begin{array}{c}\text { Pump rotation speed, rpm } \\
\text { Direction of pump rotation } \\
\text { (for the present analysis) }\end{array}$ & 0.2 & Counterclockwise \\
\hline $\begin{array}{c}\text { Pump nozzle elevation } \\
\text { above tank bottom, inches }\end{array}$ & About 12 & About 12 \\
\hline $\begin{array}{c}\text { Velocity at nozzle exit, } \\
\text { ft/sec (m/sec) }\end{array}$ & 80.8 (24.635) & 109.0 (33.213) \\
\hline $\begin{array}{l}\mathrm{U}_{\mathrm{o}} \mathrm{d}_{\mathrm{o}}, \mathrm{m}^{2} \text { sec } \\
\text { (1) }\end{array}$ & 2.268 & 1.265 \\
\hline
\end{tabular}

Note:* Bseline operating conditions

Table 2. Four different combinations of operating pump configurations in Tank 50

\begin{tabular}{|l|c|l|l|}
\hline Cases & $\begin{array}{c}\text { Number of } \\
\text { pumps } \\
\text { operated }\end{array}$ & \multicolumn{1}{|c|}{$\begin{array}{c}\text { Combinations of } \\
\text { pumps }\end{array}$} & \multicolumn{1}{|c|}{ Pump locations } \\
\hline Case-1 & 3 & $\begin{array}{l}\text { 1 Quad Volute Pump } \\
(\text { QVP), 2 SSPs }\end{array}$ & $\begin{array}{l}\text { Riser B2: 1 QVP** } \\
\text { Risers E1 and B3: 2 SSPs (Detailed } \\
\text { riser locations shown ion Fig. 1) }\end{array}$ \\
\hline Case $-2^{+}$ & $\begin{array}{c}3 \text { (Case-2a, } \\
-2 \mathrm{~b},-2 \mathrm{c})\end{array}$ & 3 SSPs* & $\begin{array}{l}\text { Risers E1, B2, and B3: 3 SSPs (See } \\
\text { Fig. 2 for sensitivity studies of } \\
\text { asynchronous and orientation cases) }\end{array}$ \\
\hline Case-3 & 2 & 2 SSPs* & $\begin{array}{l}\text { Risers B2 and B3: 2 SSPs } \\
\text { (See Fig. 3) }\end{array}$ \\
\hline Case-4 & 1 & 1 SSP* & Risers B2: 1 SSP (See Fig. 4) \\
\hline
\end{tabular}

Note:* Standard Slurry Pump

** Quad Volute Pump

${ }^{+}$Baseline operating case 


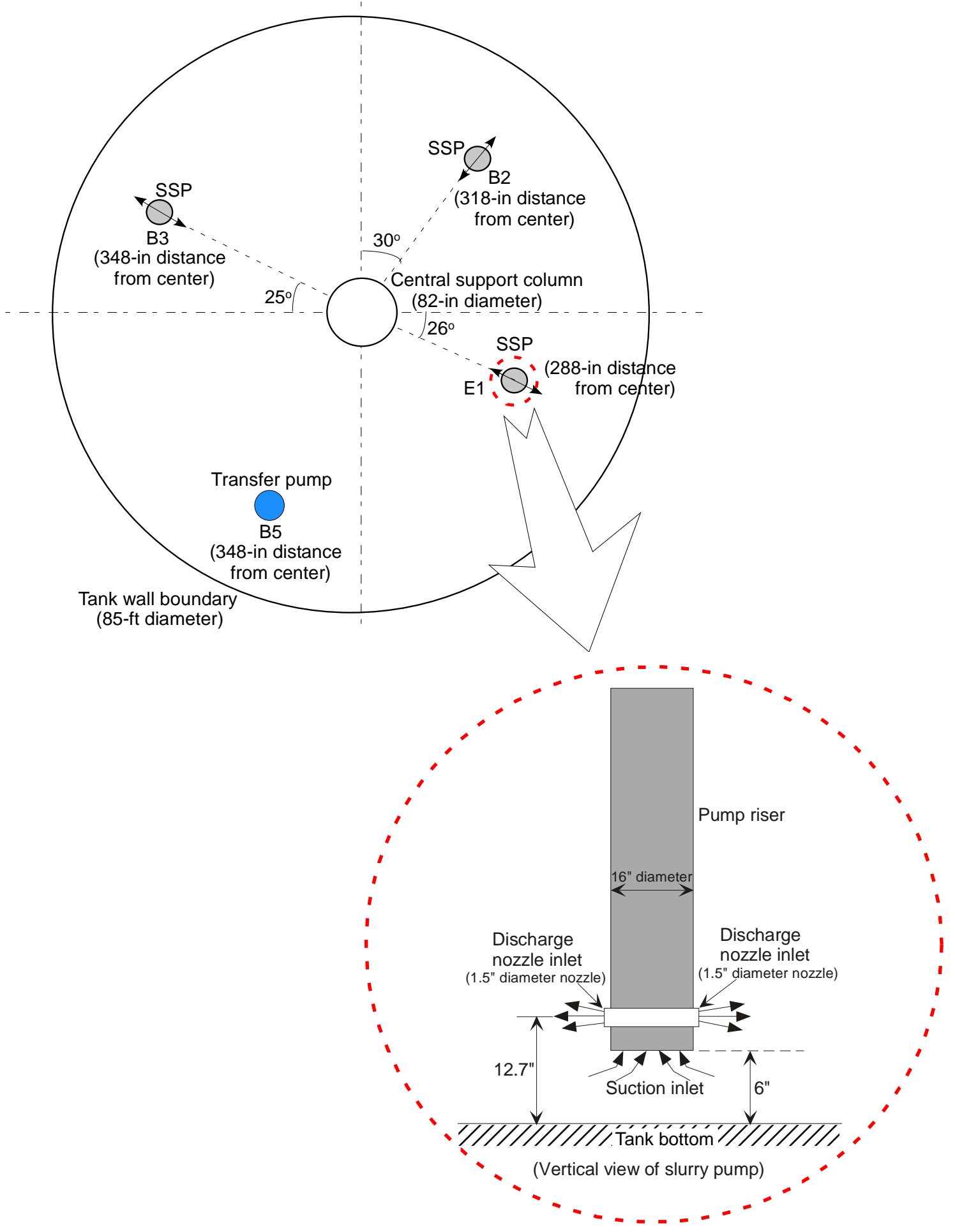

Figure 1. Geometrical configurations [2] and three-dimensional modeling domain containing three SSPS and one transfer pump in the analysis of the Tank 50 Model 


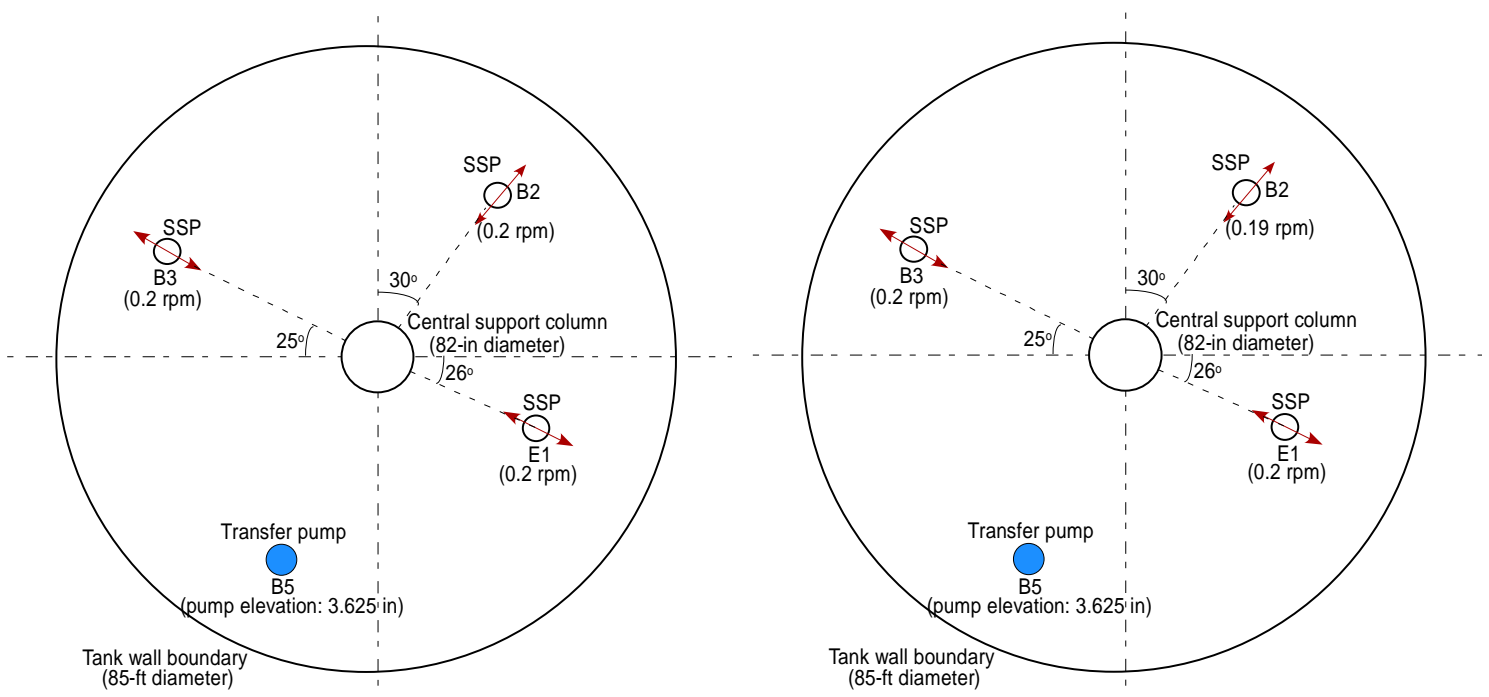

(Case-2a: All SSPs with synchronous mode) (Case-2b:B2 SSP with asynchronous mode)

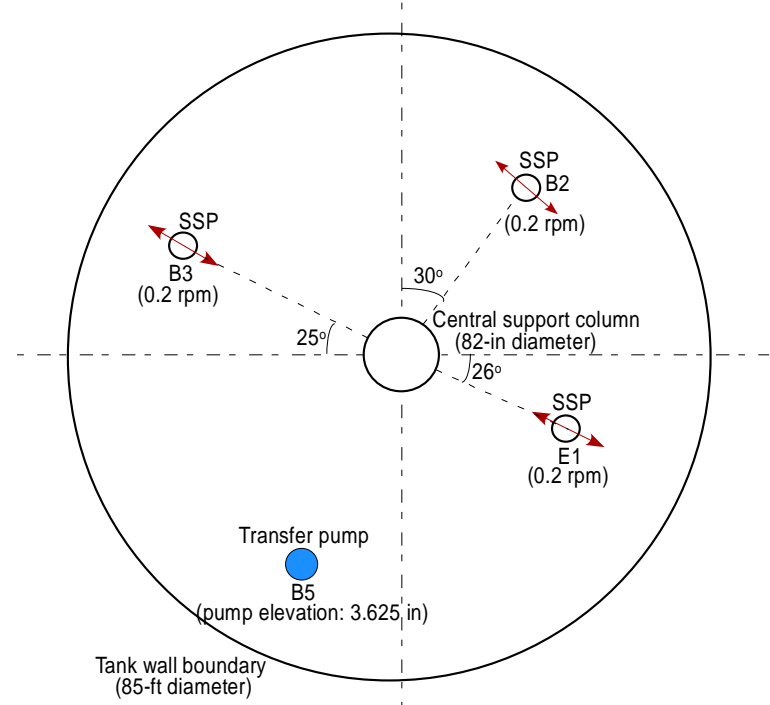

(Case-2c:All SSPs with synchronous mode, and B2 SSP with different initial orientation)

Figure 2. Three different sensitivity cases under the Case-2 study 


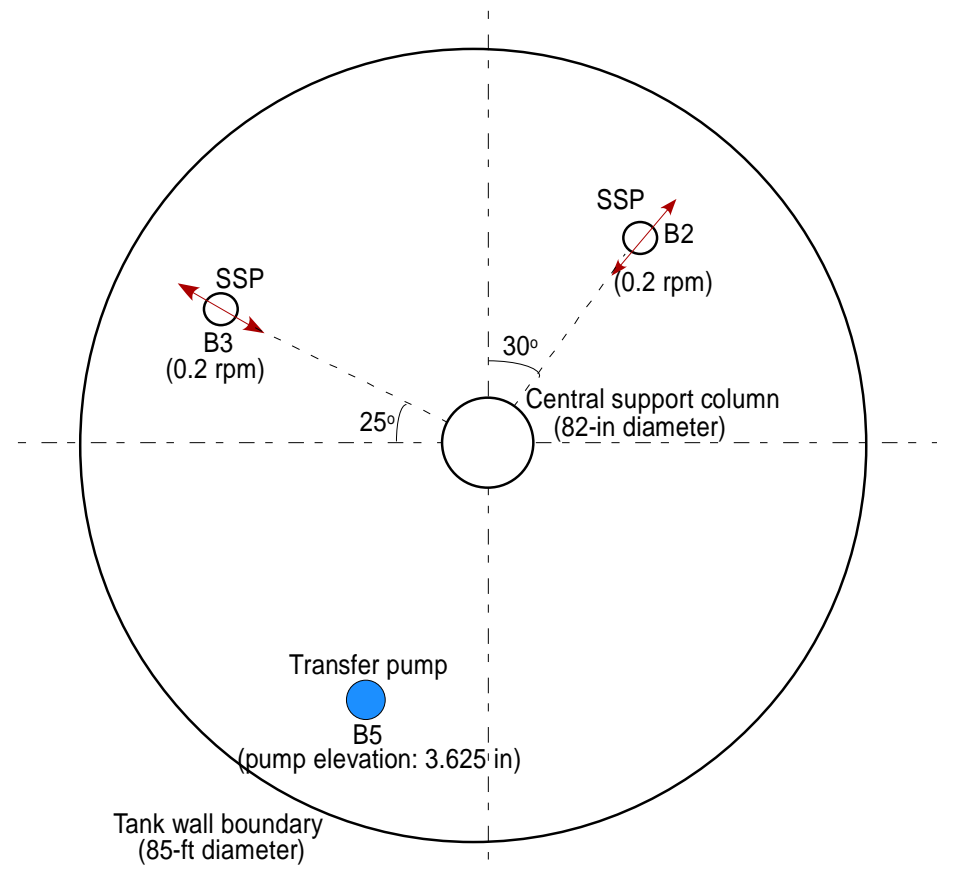

Figure 3. Pump locations for the two SSPs of the Case-3 study

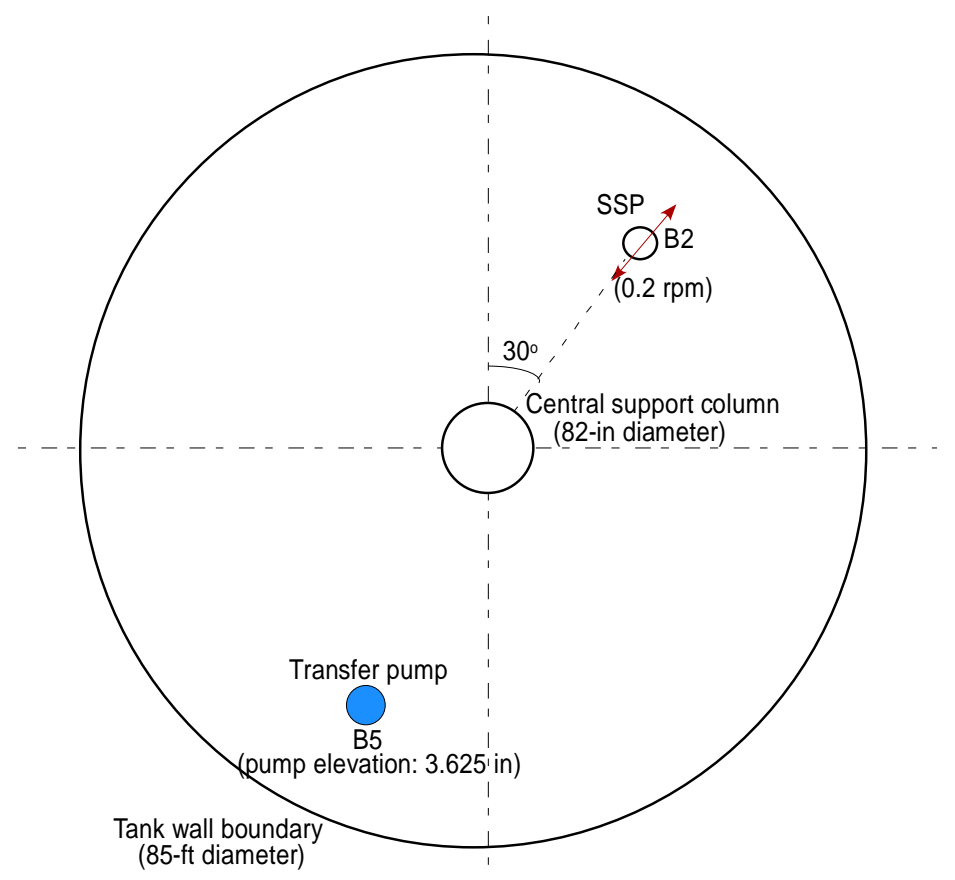

Figure 4. Pump location for the one SSP of the Case-4 study 


\section{Solution Approach and Flow Criteria}

A three-dimensional CFD approach is used to calculate flow patterns for the sludge mixing operations of Tank 50 and to evaluate sludge suspension capabilities for the tank. In previous work $[3,4]$, the model predictions were in good agreement with test data and operational observations. The same finite volume CFD code, FLUENT [5], was used here to perform the Tank 50 modeling and analysis. A prototypic geometry is modeled by a nonorthogonal and hexahedral mesh combined in a hybrid grid. The modeling domain to be used for the present analysis is presented in Fig. 1. Nominal design and operating conditions of the pumps used in the Tank 50 model are presented in Table 2. Based on the modeling domain and operating conditions, turbulent singlephase flow calculations were performed. Typical flow conditions for the slurry pump corresponds to fully-developed turbulent flow since Reynolds numbers are about $1 \times 10^{6}$ in terms of pump discharge conditions.

For the turbulence calculations, the standard $k-\varepsilon$ model was used. The threedimensional model was run in transient mode for rotating pump conditions to allow the jet flow profile to develop and ultimately approach steady state flow. In this work, local fluid velocity at any distance from the nozzle is employed as a measure of the slurrying and mixing effectiveness in Tank $50 \mathrm{H}$ operations.

The focus of the present work is suspending and mixing sludge particles with the turbulent jet generated by a slurry pump. Prior to discussing the computational modeling assumptions, some literature results for a free turbulent jet flow are reviewed briefly, since the free jet flow is similar in many respects to the bounded wall jet. The previous work [3] and the literature data [6] show that when a turbulent jet of fluid is discharged from a nozzle with a diameter $d_{0}$, it both entrains fluid and expands. Most mixing action and entrainment takes place in the region of fully-developed flow which begins at a distance of approximately eight nozzle diameters from the exit plane. The nondimensional velocity distribution $\varphi_{v}$ along the jet axis of this region for a homogeneous fluid jet is given by [3]

$$
\varphi_{v}=\left(\frac{v(x)}{U_{o}}\right)=C_{o}\left[\frac{x}{d_{o}}\right]^{-1}=C_{o} \eta^{-1}
$$

In Eq. (1), $C_{0}$ is a constant determined by the turbulence characteristics of the jet, $U_{0}$, the average velocity at nozzle exit, $v(x)$, the local velocity at a point $x$, and $x$, the distance from nozzle. For a free jet without any flow obstructions, the proportionality constant $C_{0}$ in Eq. (1) was determined to be 6.32 [6]. Since the pump discharge flow inside largescale tanks at SRS is affected by the bottom of the tank and internal flow recirculation, $\mathrm{C}_{0}$ is replaced by a constant $K$ evaluated from the previous Tank 18 calculations, rather than classical free jet theory. $K$ was found to be 4.874 [4]. The maximum axial velocity at any axial position $x$ can be estimated using Eq. (1). The equation shows that the velocity at any point in the region of established flow is directly proportional to the product, $d_{0} U_{0}$. Thus, the axial entraining distance corresponding to minimum entrainment velocity can be estimated with nozzle diameter and flow rate. Based on the literature and the previous results, it is clearly indicated that if a standard slurry pump suspends sludge solids contained in the tank, a quad-volute pump will satisfy the mixing 
Page: $\quad 8$ of 34

operations since the product $d_{o} U_{o}$ for the QVP is about twice that of the SSP as shown in Table 2.

The fluid domain for Tank 50 has both a solid wall boundary and a free surface boundary as the jet expands into the downstream region and ultimately recirculates via the suction on the bottom of the pump as shown in Fig. 1. The spreading fluid is retarded by the interaction with the wall, and the inner part of the flow may be expected to show a certain structural similarity to a boundary layer. Entrainment of quiescent fluid occurs near the outer edges of the flow, and accordingly resembles a free jet [2]. In this case, sludge particles settled near the edge of the boundary region are entrained into a turbulent zone, and they are suspended. Estimations of minimum suspension velocity and particle settling rate will be discussed for establishment of a flow velocity criterion in the subsequent sections.

\subsection{Estimation of Minimum Suspension Velocity During Jet Mixing}

The decay of the axial jet velocity and the evolution of flow patterns are important phenomena affecting sludge suspension and mixing operations. A measure of the ability to shear the sludge layer, the scouring wall shear, is directly related to the local fluid velocity. The initial movement of solids deposited on the bottom of the tank identifies the critical condition or initial scour. It is usually described by two criteria, the minimum flow velocity and the frictional shear to scour and initiate movement of deposited solids particles. From these two criteria, a local fluid velocity can be determined as a performance indicator for adequate suspension.

When liquid flow passes over a settled sludge layer containing small solids of 1 to 10 microns, the range of the sludge particles in Tank $50 \mathrm{H}$, it results in hydrodynamic forces being exerted on individual particles in the layer. For a particular stationary sludge layer, a condition is eventually reached in which particles in the movable bed are not able to resist the hydrodynamic forces and solids in the top layer start to lift. Average flow velocity, particle size and density, and slurry flow regime are key parameters in determining the transport patterns of particles in a slurry $[3,4]$. The critical velocity is defined as the minimum velocity that can initiate the movement of the solids deposited near the bottom of the tank. Following the previous works [3], a literature correlation [7] for the critical velocity $V_{c}$ was used.

$V_{c}=\left(\frac{d}{H}\right)^{-0.1} \sqrt{2.5 g d\left(\frac{\rho_{s}}{\rho_{f}}-1\right)}$

In Eq. (2), $d$ and $H$ are the particle diameter and tank liquid level, respectively. $\rho_{s}$ and $\rho_{f}$ are solid and fluid densities, respectively. When the flow velocity required for sludge transport and suspension is exceeded, the solid-laden flow can be treated as a suspended fluid-solid mixture. In this case, although solid particles are suspended by the continuous-phase flow, the local amount of solids suspended by the fluid may not be uniform over the entire domain of the tank fluid. However, the present work assumes that when the flow velocity required for sludge transport and suspension is exceeded and transient turbulent kinetic energy is dissipated throughout the tank in a quasi-steady condition, the solid-laden flow can be approximated as a homogeneous fluid.

The concept of "quasi-steady" being used in this report refers to a condition in which the long term evolution of the observed flow parameters seems to have ceased. It is a qualitative assessment that cannot be interpreted as either steady-state (time derivatives equal zero) or periodic, but rather an assessment that the flow has reached its long term 
character, and that no conclusions based on the flow are likely to undergo further change. The use of this concept to estimate when the tank fluid can be approximated as homogenous is supported by homogeneous mixing times using experimental results available in the literature [8]. Thus, a flow velocity required for sludge suspension and a turbulent eddy viscosity associated with transient turbulent energy dissipation will be used as criteria for particle suspension and a local mixing to estimate the time required to produce a homogeneous slurry output from different pump combinations and operations in Tank $50 \mathrm{H}$.

Figure 5 shows minimum suspension velocities for particles of different mono-sized particle systems with a particle specific gravity (spg) of 2.5 and a fluid spg of 1.2 with a full tank level of 290 inches. Figure 6 shows the velocity required to suspend 10-micron solids below which the tank will experience sedimentation. From these results, the present work will use a local flow velocity of $0.07 \mathrm{~m} / \mathrm{sec}$ as the minimum velocity criterion for solid suspension. Thus, local fluid velocity at any distance from the nozzle is employed as a measure of the slurrying and mixing criterion.

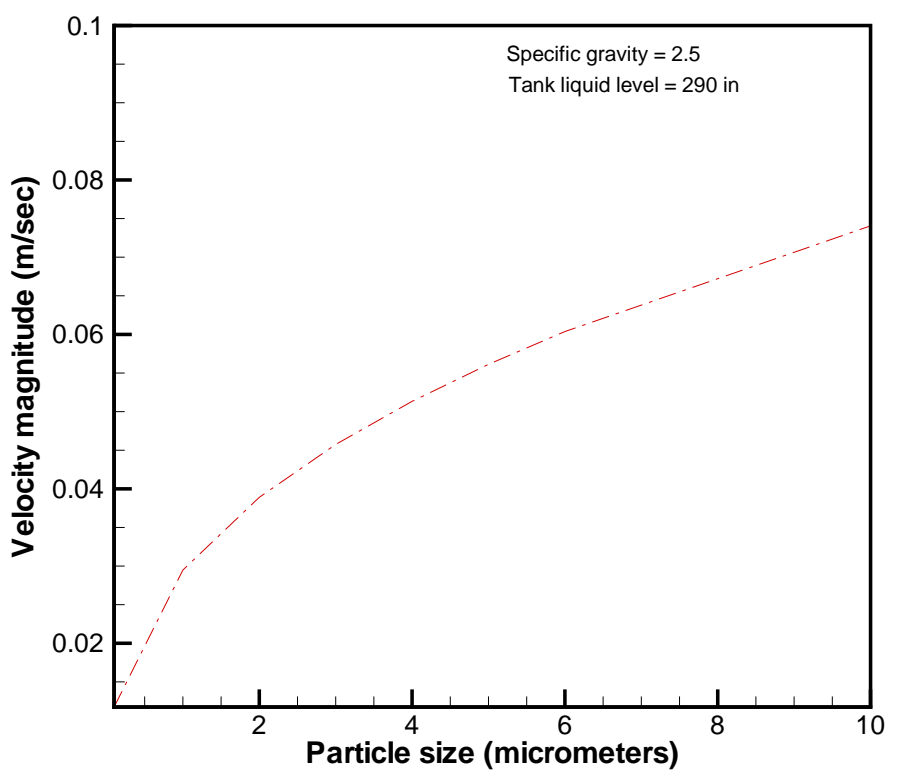

Figure 5. Minimum velocity required to suspend particle from the floor 


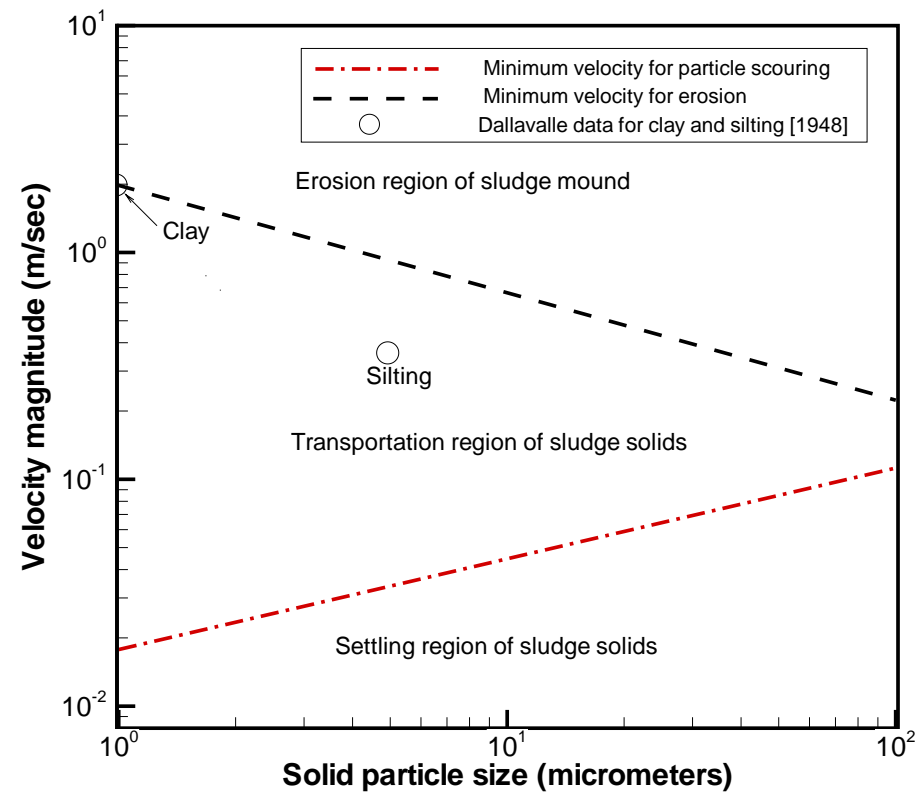

Figure 6. Velocity criteria for deposition, scouring, and erosion of sludge solids for the present operating conditions

\subsection{Settling Velocity for Mono-sized Particles in Stagnant Fluid}

The drag force on an isolated solid particle moving in an infinite expanse stagnant fluid is represented by the equation,

$F_{D}=\frac{1}{2} C_{D} \rho_{f} v_{f}^{2} A_{p}$

In Eq. (3) $\rho_{f}$ is density of fluid, $A_{p}$ represents the projected cross-sectional area of the particle perpendicular to the direction of motion, and $C_{D}$ is the drag coefficient at the surface of particle when a solid particle is falling downward with velocity $v_{f}$. The drag coefficient $C_{D}$ is dependent on particle shape and flow regime in terms of the Reynolds number $(R e)$.

For the case of free settling of spherical particles of density $\rho_{p}$ at a constant velocity and without interaction or hindering effects due to the presence of other particles, the drag force $F_{D}$ equals the force of gravity $F_{G}$, including the buoyancy force of the particle of solid volume $V_{p}$ submerged in a quiescent fluid.

$$
\begin{aligned}
& F_{G}=V_{p}\left(\rho_{p}-\rho_{f}\right) g \\
& =F_{D}
\end{aligned}
$$

After some algebraic manipulations, eqs. (3) and (4) become

$$
v_{f}=\left[\left(\frac{2}{C_{D}}\right)\left(\frac{V_{p}}{A_{p}}\right) g \frac{\left(\rho_{p}-\rho_{f}\right)}{\rho_{f}}\right]^{0.5}=\left[\left(\frac{2}{C_{D}}\right) \varphi g \frac{\left(\rho_{p}-\rho_{f}\right)}{\rho_{f}}\right]^{0.5}
$$


When the particle has a spherical shape with diameter $d_{p}$, the ratio $(\varphi)$ of the particle volume to its projected area in Eq. (5) is $(2 / 3) d_{p}$. Then,

$v_{f}=\left[\left(\frac{4}{3 C_{D}}\right) d_{p} g \frac{\left(\rho_{p}-\rho_{f}\right)}{\rho_{f}}\right]^{0.5}$

In this situation, the flow is assumed to be slow viscous, or Stokes's flow. In 1850, Stokes derived the solution for viscous flow past a sphere at small values of the Reynolds number by using the momentum equation without inertia terms in a spherical polar coordinate system and by fitting no-slip boundary conditions at the spherical surface [9]. His result for drag force acting on the sphere was:

$$
F_{D}=3 \pi \mu_{f} d_{p} U_{o}
$$

where $U_{o}$ is the undisturbed free stream velocity.

When the particle velocity relative to the bulk fluid is equal to the undisturbed free stream velocity in Eq. (7) and $\mathrm{Re}<0.6$, the drag coefficient $\mathrm{C}_{\mathrm{D}}$ in Eq. (5) corresponding to the Stokes formula, Eq. (7), can be expressed as

$$
C_{D}=\frac{F_{D}}{\frac{1}{8} \rho_{f} v_{f}^{2}\left(\pi d_{p}^{2}\right)}=\frac{24}{R e}
$$

The Reynolds number, Re, the dimensionless parameter used in Eq. (8), is defined in terms of particle diameter $d_{p}$ and velocity $v_{f}$ relative to the fluid medium with density $\rho_{f}$ and viscosity $\mu_{f}$ as,

$$
R e=\frac{d_{p} \rho_{f} v_{f}}{\mu_{f}}
$$

When the drag coefficient $C_{D}$ in Eq. (6) is replaced by Eq. (8), settling velocity for a single spherical particle in quiescent fluid becomes

$v_{f}=\frac{g d_{p}{ }^{2}\left(\rho_{p}-\rho_{f}\right)}{18 \mu_{f}}$

It must be emphasized that Stokes's drag coefficient is only applicable at very low velocities and valid for values of Reynolds number less than about 1 . This limit for Stokes flow corresponds to viscous dominant settling velocity.

At larger values of the Reynolds number, the inertial terms exercise an increasing influence on the flow dynamics. From the literature [13], the drag coefficients for the spherical particle submerged in the fluid are as follows:

$$
\begin{aligned}
& C_{D} \approx \frac{18.5}{R e^{0.6}} \text { for } 1 \leq R e<10^{3} \text { (intermediate flow regime) } \\
& C_{D} \approx 0.44 \text { for } 10^{3} \leq R e<10^{5} \text { (Newton's flow regime) }
\end{aligned}
$$

The study of settling phenomena has been performed by a considerable diversity of approaches. The literature information [11] has suggested that the motion of a typical single particle should be influenced by both the motion and the presence of the other 
Page: 12 of 34

particles. The main effect of the motion of the other particles is to cause a return flow of liquid, while the presence of the other particles produced an effect similar to an increase in the viscosity of the dispersing liquid. In the literature correlations [13], the velocity for flow past a single sphere was used in order to obtain an equation relating the settling velocity of a suspension of mono-size spherical particles to the volume concentration of the solid phase.

Table 3 shows a useful correlation for relative settling velocity $V_{r}$ in terms of solids volume concentration, $c$. Relative settling velocity $V_{r}$ is defined as

$$
V_{r}=\frac{v_{s}}{v_{f}}
$$

In Eq. (12), $v_{s}$ is the settling velocity in a multi-particle system, and $v_{f}$ is the settling velocity for a single particle in a fluid.

The downward motion of the particles must cause an upward flow of liquid, and the velocity of this flow averaged for the whole flow cross-section of the tank must be the liquid fraction $(1-c)$ times the solid settling velocity of particles, allowing only for return flow of liquid when $c$ is defined as the solids volume fraction of the solid-fluid mixture. In addition, the presence of other particles also impedes the motion of a given particle in the same way as if there were an increase in the viscosity of the liquid, so that the effective relative viscosity would reduce the settling rate of the suspended particles. Thus, the updated literature correlations [11] for settling velocity within a solution containing low solids volume fraction were formulated considering these two factors.

$v_{s}=v_{f} f_{1}(c) f_{2}(c)$

In Eq. (13) $f_{1}$ and $f_{2}$ are empirical functions associated with a return flow effect due to the falling of the particles and a hindering effect of the particle precipitation due to the increased effective viscosity, respectively. These two functions were assumed to be dependent only on the solid volume fraction of suspension, $c$.

Figure 7 shows single free-fall velocities and multi-particle settling velocities as function of solid particle diameters in water. The calculations were performed by using a Stokes's flow approach (Eq. (10)) and the literature correlation for the settling rate of mono-sized spherical particles.

A typical literature correlation for relative settling velocity is shown in Table 3 . It can be used to examine the interference or hindering effects of particle settling due to presence of the other particles for the range of solid particle concentrations. The results shown in the literature indicate that settling velocities of particles in a multi-particle system are different depending on the particle shape and solid concentration. The settling velocity of spherical particles was estimated for different solid contents in a slurry. The Oliver (1961) correlation was used to capture the hindering effect of particle settling in a multiparticle system. Specific information on the waste characteristics for the present work assumes that the insoluble solids have particle sizes from 5 to 10 microns with a concentration of $25 \mathrm{wt} \%$, a slurry solids density of $2500 \mathrm{~kg} / \mathrm{m}^{3}$, and a slurry viscosity of 2 $x 10^{-3} \mathrm{~Pa}-\mathrm{s}$ for conservative estimate of the sludge settling rate. The volume concentration of particles in the continuous fluid phase is one of the key parameters associated with flow pattern and slurry characteristics. The weight fraction $\mathrm{W}$ for solids can be converted to volume fraction c for given densities of the fluid and solid phases. 
$c=1-\left\{\frac{\left(\frac{\rho_{f}}{\rho_{s}}\right)}{\left(\frac{1}{W}-1\right)}+1\right\}^{-1}$

where $\rho_{f}$ and $\rho_{\mathrm{s}}$ are the densities of fluid and solid, respectively.

From Eq. (14) volume fractions of slurry solids (c) can be calculated as about 0.12 for the present operating conditions when their weight fractions in a slurry flow are 0.25. The results for settling velocity of the sludge particle are summarized in Table 4 . It is noted that a 10-micron sludge particle takes about 19 minutes to settle without hindering effects from the inlet of the transfer pump to the tank floor.

Table 3. Literature correlation for relative settling velocity based on solid volume fraction (relative settling velocity $V_{r}$ is defined by Eq. (12)).

\begin{tabular}{|c|c|c|}
\hline Authors (Year) & Relative settling velocity correlations & Approach method \\
\hline Oliver (1961) & $V_{r}=\left(1-0.75 c^{1 / 3}\right)(1-2.15 c)$ & $\begin{array}{c}\text { Theoretical and empirical } \\
\text { work }\end{array}$ \\
\hline
\end{tabular}

Table 4. Settling velocity and average settling times for different sludge particle sizes in slurries containing two different solid contents ( $\rho_{f}=1.0 \mathrm{gm} / \mathrm{cc}, \rho_{\mathrm{s}}=2.5 \mathrm{sg}$ ).

\begin{tabular}{|c|c|c|c|c|c|c|}
\hline \multirow{2}{*}{$\begin{array}{c}\text { Particle } \\
\text { size } \\
\text { (microns) }\end{array}$} & \multicolumn{2}{|c|}{ Settling velocity (in/sec) } & \multicolumn{3}{c|}{ Average settling time (min.) ${ }^{\star}$} \\
\cline { 2 - 7 } & $\begin{array}{c}0 \text { vol\% } \\
\text { solids }\end{array}$ & $\begin{array}{c}5 \text { vol\% } \\
\text { solids }\end{array}$ & $\begin{array}{c}12 \text { vol\% } \\
\text { solids }\end{array}$ & $\begin{array}{c}0 \text { vol\% } \\
\text { solids }\end{array}$ & $\begin{array}{c}5 \text { vol\% } \\
\text { solids }\end{array}$ & $\begin{array}{c}12 \text { vol\% } \\
\text { solids }\end{array}$ \\
\hline 5 & 0.00080 & 0.00052 & 0.00038 & 76 & 116 & 159 \\
\hline 10 & 0.0032 & 0.0021 & 0.0015 & 19 & 29 & 40 \\
\hline 15 & 0.0073 & 0.0047 & 0.0034 & 8 & 13 & 18 \\
\hline
\end{tabular}

Note:* Average time for solid particle to travel 3.625-in distance down to the tank floor under a slurry fluid containing a given amount of solid contents

**Fluid medium containing single particle 


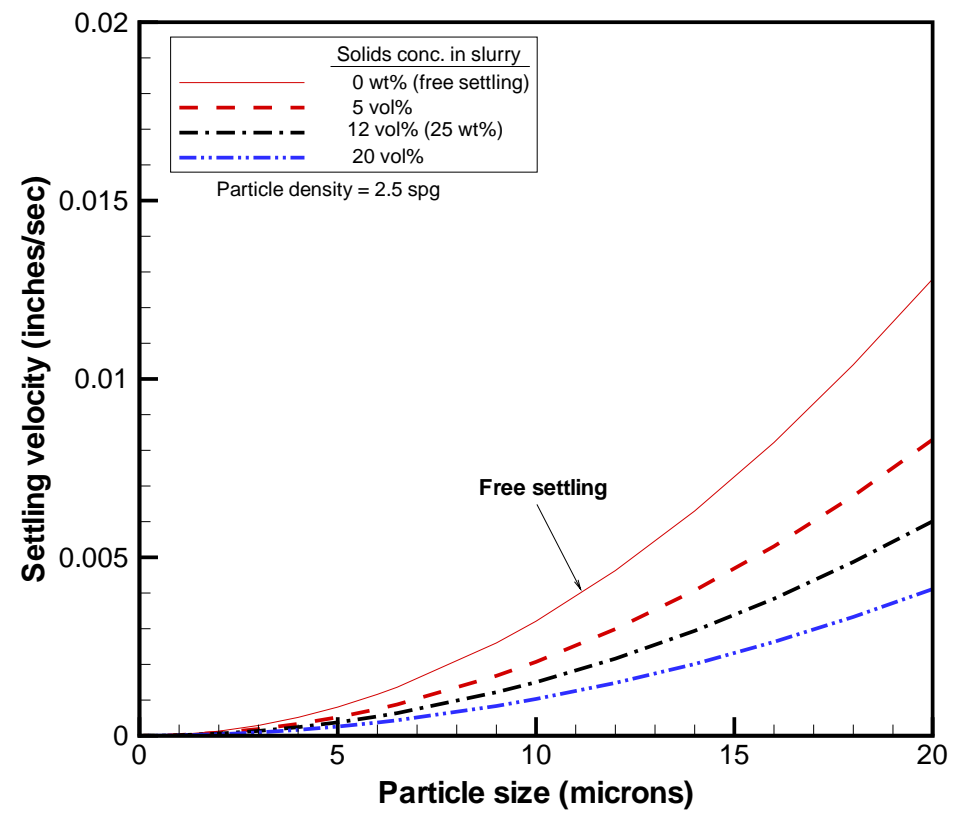

Figure 7. Particle settling velocity as function of particle sizes for different solid contents in a slurry of $2.5 \mathrm{spg}$ solids.

\subsection{Mixing Criterion for Sludge Particles in Tank 50H}

The criteria by which turbulent jet flows entrain and mix sludge particles from the sludge layer were established by using two key parameters obtained from the previous work $[3,4]$ and the literature [8]. One is minimum velocity magnitude required to pick up the particles. The other one is mixing time associated with turbulent energy dissipation rate and eddies. The mixing time will be evaluated from the literature correlation [8]. The correlation for mixing time was empirically obtained in terms of tank diameter and energy dissipation rate when the solids are fully suspended in the tank. The energy dissipation rate was determined by the jet path length and the velocity at that location. The mixing time is closely related to the momentum dissipation time.

The minimum hydraulic force derived by the first criterion, which is just sufficient to pick up solids from the settled sludge layer, is referred to as a critical scouring velocity in the literature. It will be a function both of the particle properties and of their arrangement in the sludge layer. As a second criterion, turbulent eddies related to the turbulent energy dissipation rate disrupt the viscous sublayer and impinge directly on the surface of the solids, which were already suspended by fluid motion. Thus, eddies created by energy dissipation tend to drive turbulent mixing over the flow domain of the tank. For the present analysis, it is suggested that when quasi-steady flow patterns established by jet pumps can suspend particles, then the time to reach a steady state eddy distribution is close to the time required to achieve spatial mixing in the tank. 


\subsection{Tank 50 Model and Assumptions}

Figure 1 shows geometrical configurations and three-dimensional modeling domain as modeled in the CFD environment for the multi-pump simulations including the internal flow obstructions. For the simulations, a series of transient modeling calculations was performed with rotating pumps until a quasi-steady flow pattern near the inlet location of the transfer pump is established. For a rotating model, the direction of the pump discharge was changed in discrete $15^{\circ}$ increments counterclockwise. Each pump stayed fixed for 12.5 seconds at each direction, resulting in a simulated rotational speed of 0.2 rpm. Initial pump orientations for the rotating pump model are illustrated in Figs. 2 to 4. The pump was started in a quiescent tank.

Physical model assumptions and geometrical simplifications are listed as follows:

- There are no solid obstructions in the tank other than tank wall, major pump support structures, and one central support column as shown in Fig. 1.

- The pump nozzles for transient operations are rotated counterclockwise and include asynchronous rotatation effects. In this case, the asynchronous rotation means different rotational speed.

- The working liquid is water at $40{ }^{\circ} \mathrm{C}$. A temperature slightly different from this value will not have a significant effect on flow patterns.

- $\quad$ The liquid region is bounded by a free surface at constant atmospheric pressure.

- The model is isothermal. No energy equation is calculated.

- The flow in the entire model domain is assumed to be turbulent to give a reasonable representation of the liquid jet leaving the pump nozzle.

- $\quad$ The wavy motion of the free surface due to the interaction with the discharge jet is neglected. Literature data [10] show that the surface wave effect is negligible when the ratio of liquid height above the nozzle to nozzle diameter is larger than 2.5. For a slurry mixer in Tank 50, the ratio is about 193 for the 290-in liquid level case.

Three-dimensional numerical simulations are made for the Tank 50 modeling analysis. About 800,000 nodes are used to represent the three-dimensional computational domain. This number was established from sensitivity studies of computational meshes. Mesh density is significantly higher in the vicinity of the pump discharge to capture the flow behavior relative to the nozzle diameter. The characteristic mesh dimension is much greater in regions far from the nozzle and other solid structures to keep the total number of nodes manageable. 


\section{Results and Discussion}

A Tank 50 model has been developed by a CFD approach to include several internal flow obstructions such as central support column and major pump housings in the flow domain and analyses performed to estimate circulation flow patterns within Tank 50 to evaluate the ability of the slurry pumps to suspend the sludge solids remaining in the tank. The mixing pumps are considered to be rotational for flow pattern estimation of the jet pump. Asynchronous operation mode and different initial pump orientations were also considered for examining the impact of mixing performance for normal pump configurations. In the analysis, a flow velocity criterion was used as the primary indicator of the ability to scour sludge solids and to suspend them, based on the solution method established in the previous section.

The primary model was simulated with the design and operating conditions as provided in Table 1 and Table 2, to evaluate flow circulation patterns for the sludge mixing operations of Tank 50. The model was also used to perform sensitivity analyses for different numbers of pumps, and various pump operating conditions such as asynchronous rotation speed or initial pump orientation.

As discussed earlier, Case-2 was selected as the baseline modeling conditions, since the product $d_{o} U_{o}$ for the QVP is about twice that of the SSP as shown in Table 1 . Thus, if Case-2 has sufficient flow to suspend and mix the solids, Case-1 will satisfy the flow mixing requirement. For an assessment of the impact of different pump combinations on the tank mixing, Case-3 considered one pump failure among the three pumps as shown in Fig. 3. Case-4 simulated operation with a single standard slurry pump as the worst scenario. Detailed operating conditions of Tank 50 used for the present analysis are provided in Table 2.

When three standard slurry pumps are synchronously operated in Risers E1, B2, and B3, transient velocity magnitudes at the inlet of transfer pump in Riser B5 are presented in Fig. 8. The baseline results of Case-2a in Fig. 2 are based on the initially quiescent fluid field and 290-in tank level. The calculations show that it takes about 5 minutes to establish quasi-steady flow patterns. It is noted that although fluid flow near the inlet of the transfer pump varies from $0.07 \mathrm{~m} / \mathrm{sec}$ to $0.5 \mathrm{~m} / \mathrm{sec}$ with the transient pump orientations, the established flow keeps 10-micron particles suspended during synchronous pump rotations. As shown in Table 4, the 10-micron particle settles in about 19 minutes under free settling conditions. Figure 9 shows the flow patterns of pump nozzle orientations, A, B, and C, as indicated on Fig. 8. The established flow patterns generated about 2 to $5 \%$ turbulence intensity at the inlet region of the transfer pump as shown in Fig. 10. The corresponding turbulent energy dissipation rate, $\varepsilon$, and turbulent eddy viscosity, $\mu_{\mathrm{t}}$, are shown in Figs 11 and 12, respectively. These results show that transient values due to different initial turbulence values disappear in about 6 minutes, leading to the establishment of quasi-steady values. It is indicated that steady turbulent mixing is established in about 6 minutes after the beginning of the pump operations as a result of the established flow field keeping the sludge particles suspended as shown in Fig. 8. When a single-jet pump is operated in a 42.5 -ft radius tank, about 10 minutes is required for homogeneous mixing over the entire domain of the tank, according to the literature correlation [8]. This mixing time is consistent with the modeling results.

When all of three standard slurry pumps are operated synchronously, Figure 13 shows velocity magnitude distributions for the vertical and horizontal planes crossing the inlet region of the transfer pump (Riser B5) at transient time of 240 seconds, which 
Page: 17 of 34

corresponds to transient point A in Fig. 8. Transient snapshots for fluid motions at other points in Fig. 6, B and C, are shown in Figs. 14 and 15. The red zone in the figures has local velocity higher than $0.07 \mathrm{~m} / \mathrm{sec}$, the minimum velocity required to pick up 10-micron sludge solids. Figure 16 shows spatial distributions for turbulent intensity and eddy viscosity at transient time of 300 seconds.

When the slurry pumps are operated asynchronously, Figure 17 shows quantitative comparisons of transient fluid velocity magnitudes at the inlet of the transfer pump between the cases with synchronous and asynchronous operations. Random initial pump orientations are also considered to examine their impact on flow patterns. All the results are quantitatively compared in Fig. 18 and show that all transient flow magnitudes in the figure are larger than the suspension velocity of $0.07 \mathrm{~m} / \mathrm{sec}(2.8$ inches/sec). The calculation results show that when three standard slurry pumps at Riser E1, B2, and B3, are operated, sludge solids in the tank are well suspended and they are spatially spread over the flow domain and homogeneously mixed by turbulent eddy motion.

As shown in Table 1, operations of two standard slurry pumps were considered as Case3. For this calculation, the pump located at Riser E1 was assumed to be inoperable as a conservative case. The calculation results for Case-2a and Case- 3 are compared in Figs. 19 and 20. The results show that when two pumps are operated, local velocity magnitudes are smaller than minimum scouring velocity, $0.07 \mathrm{~m} / \mathrm{sec}$, for about a 70 -sec period between two adjacent peak values as shown in Fig. 19. The sludge solids will not settle during this period since the free settling time of 10-micron sludge solids is about 19 minutes, much longer than 70 seconds. Although the two-pump operation has the potential to keep sludge particles suspended, it is not recommended for Tank 50 mixing operation because the current analysis does not provide a quantitative evaluation of solids content in the fluid domain.

When two slurry pumps of Case- 3 are operated, Figure 21 shows the velocity magnitude at the vertical and horizontal planes crossing the inlet region of the transfer pump TTP at Riser B5 at a transient time 300 seconds. In the figure, the red zone has local velocity magnitude higher than $0.07 \mathrm{~m} / \mathrm{sec}$, which is required to scour and transport 10-micron sludge solids. For a one pump configuration, Case-4, with the same operating conditions as Case-2, the modeling results show that there is insufficient flow to keep sludge solids suspended vertically and horizontally throughout the tank domain as shown in Fig. 22.

Figure 23 compares quasi-steady snapshots of flow velocity magnitudes between the one-pump case of Case-4 and the two-pump operation of Case-3 at the horizontal plane crossing the inlet region of the transfer pump. In the figures, the red zone has local value higher than $0.07 \mathrm{~m} / \mathrm{sec}$, which is minimum velocity required for 10-micron sludge pickup. Transient velocity magnitudes at the inlet region of the transfer pump are quantitatively compared under various pump combinations in Fig. 24. The results show that when one standard slurry pump located at a distance from the transfer pump is operated in Tank 50, local velocity magnitudes near the inlet of transfer pump reach at most about $0.1 \mathrm{~m} / \mathrm{sec}$. Based on the modeling results, it is shown that the single-pump case does not provide acceptable mixing results.

The experimental results available in the literature indicate that local turbulent eddies related to kinetic energy dissipation control the mixing rate for the whole system domain. As discussed earlier, two criteria have been applied to the assessment of acceptable mixing operations under different combinations of pump operations. When flow patterns are acceptable for keeping the sludge suspended, turbulent eddies in far-field region of 
Page: 18 of 34

the jet pump are examined for the assessment of the mixing time to achieve spatially homogeneous mixing. Figure 25 shows a qualitative comparison of quasi-steady snapshots of turbulent eddy viscosity at the horizontal plane crossing the inlet region of the transfer pump. The red region in the figure has local eddies higher than $1 \mathrm{~kg} / \mathrm{m}$-sec, which is the minimum level of large-scale eddies needed to mix sludge solids in the flow domain when compared to the literature mixing time. Quantitative comparisons of quasisteady turbulent eddies are made in Fig. 26. The results clearly show that single pump operation provides the smallest eddies in far-field region of the pump jet. All the results are summarized in Table 5. It is concluded that two-pump operation of Case-3 provides marginal level of sludge suspension and turbulent mixing, while one-pump case of Case4 does not provide acceptable flow patterns and turbulent eddies for good mixing. 


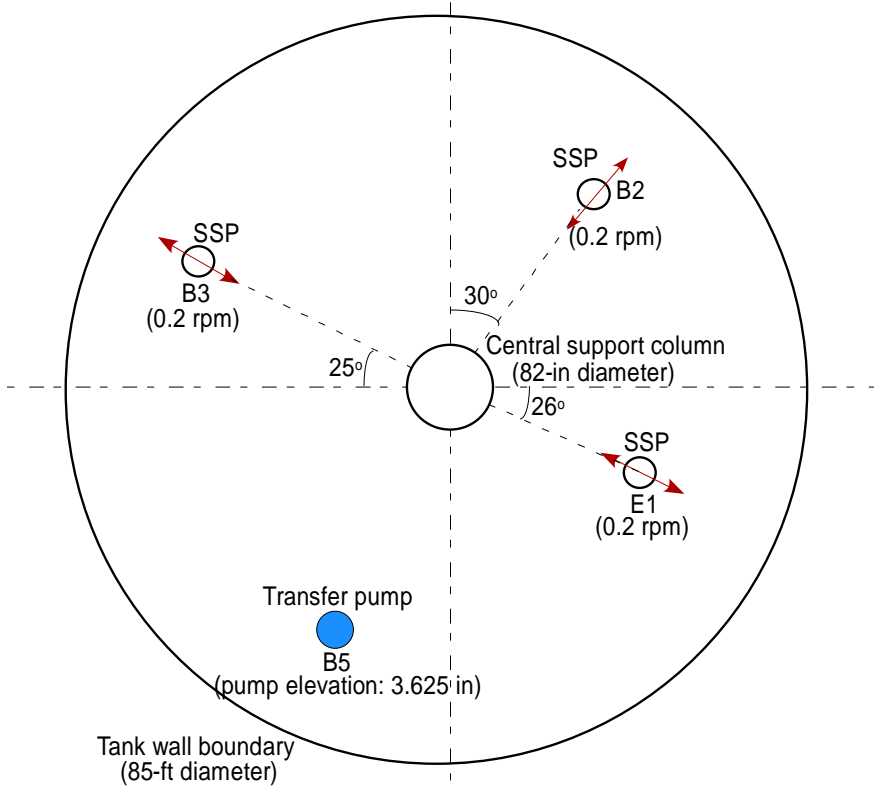

(Initial SSP orientations of Case-2a)

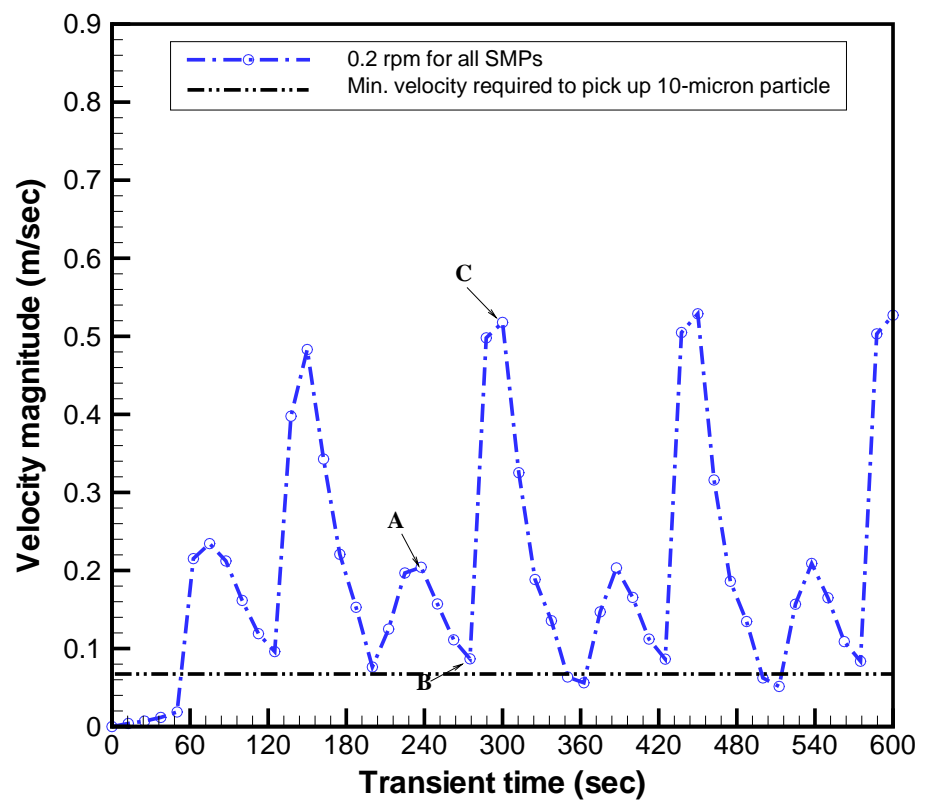

Figure 8. Transient velocity magnitude around the inlet region of TTP (Riser B5) under the baseline pump orientations of Case-2a (See Fig. 9 for flow patterns at points $A, B$, and C.) 

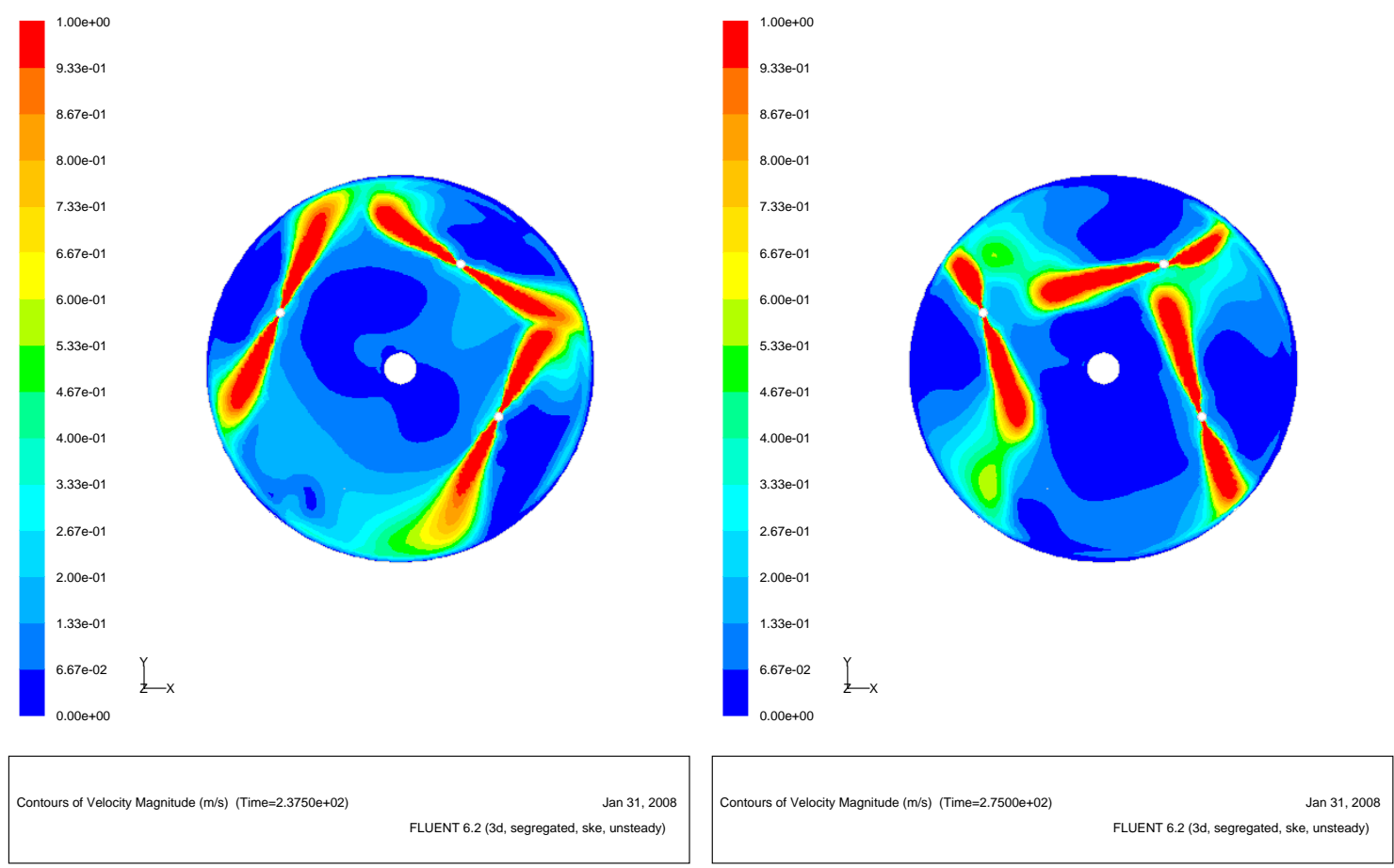

$($ Time $=240$ sec: location A in Fig. 6) $($ Time = 275 sec: location B in Fig. 6)
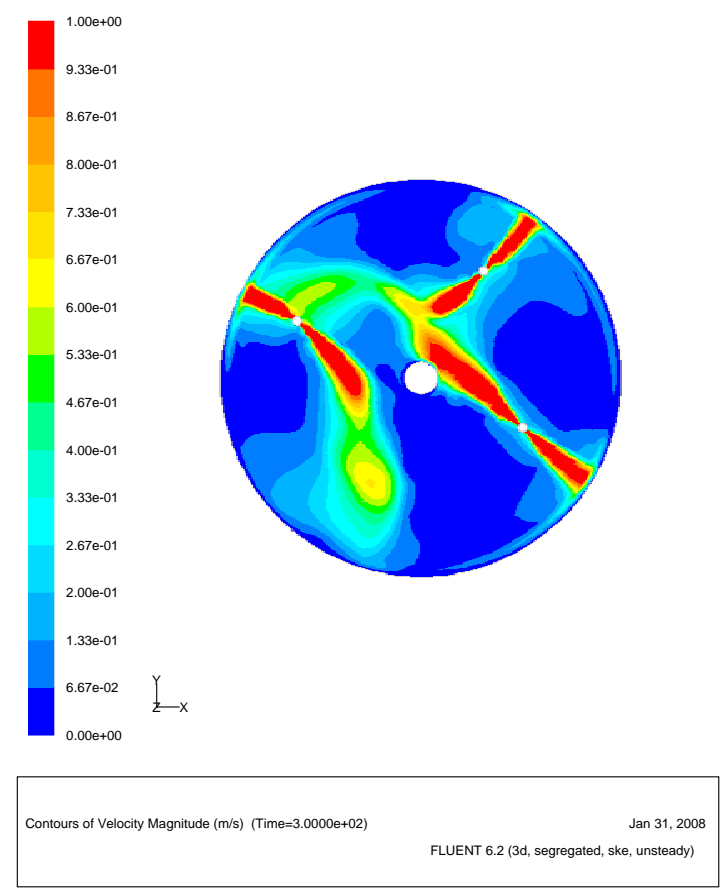

(Time $=300$ sec: location C in Fig. 6)

Figure 9. Pump nozzle orientations for three locations of Fig. 6 at the nozzle discharge plane in Tank 50 , showing the red color representing local velocity magnitude higher than $1 \mathrm{~m} / \mathrm{sec}$. 


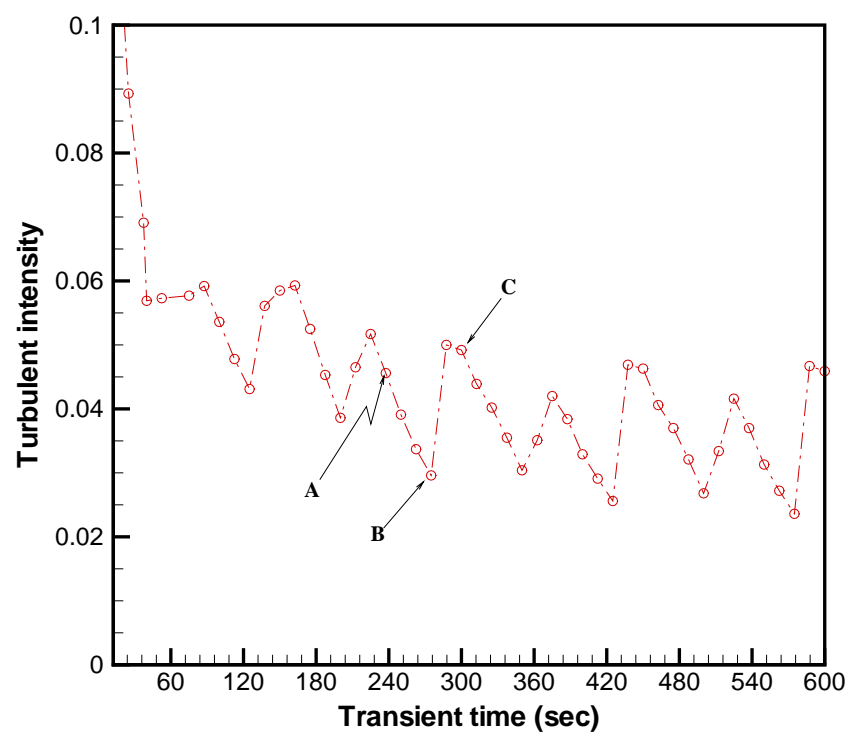

Figure 10. Turbulent intensity around the inlet region of TTP (Riser B5)

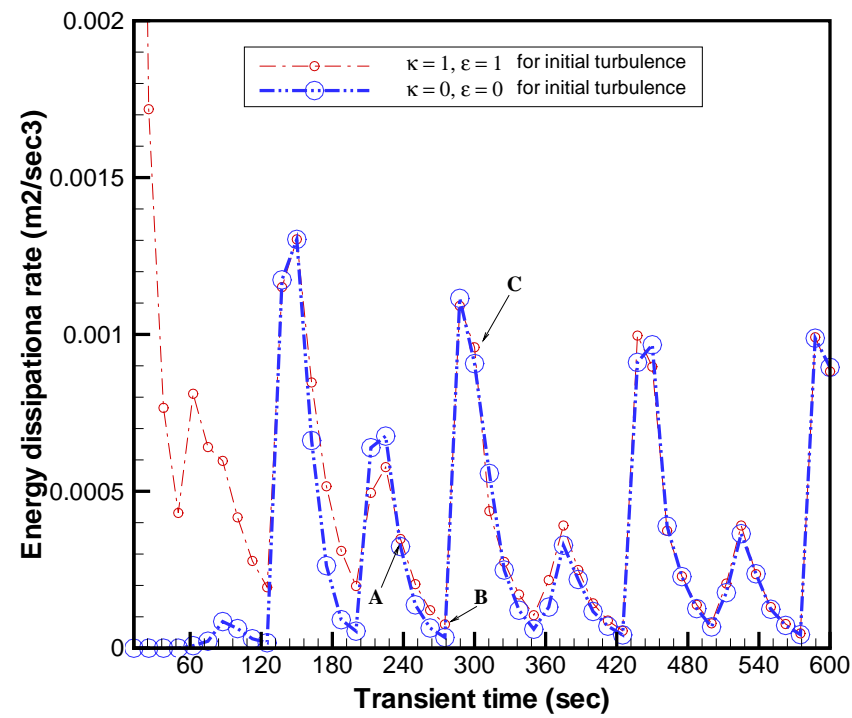

Figure 11. Turbulent energy dissipation rate around the inlet region of TTP (Riser B5) 


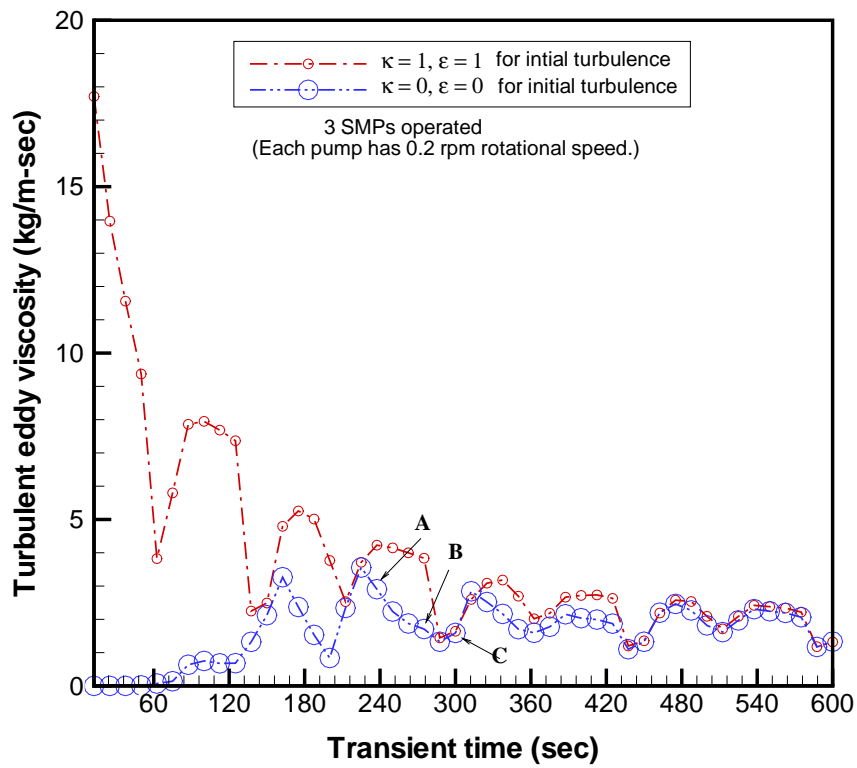

Figure 12. Turbulent eddy viscosity around the inlet region of TTP (Riser B5)
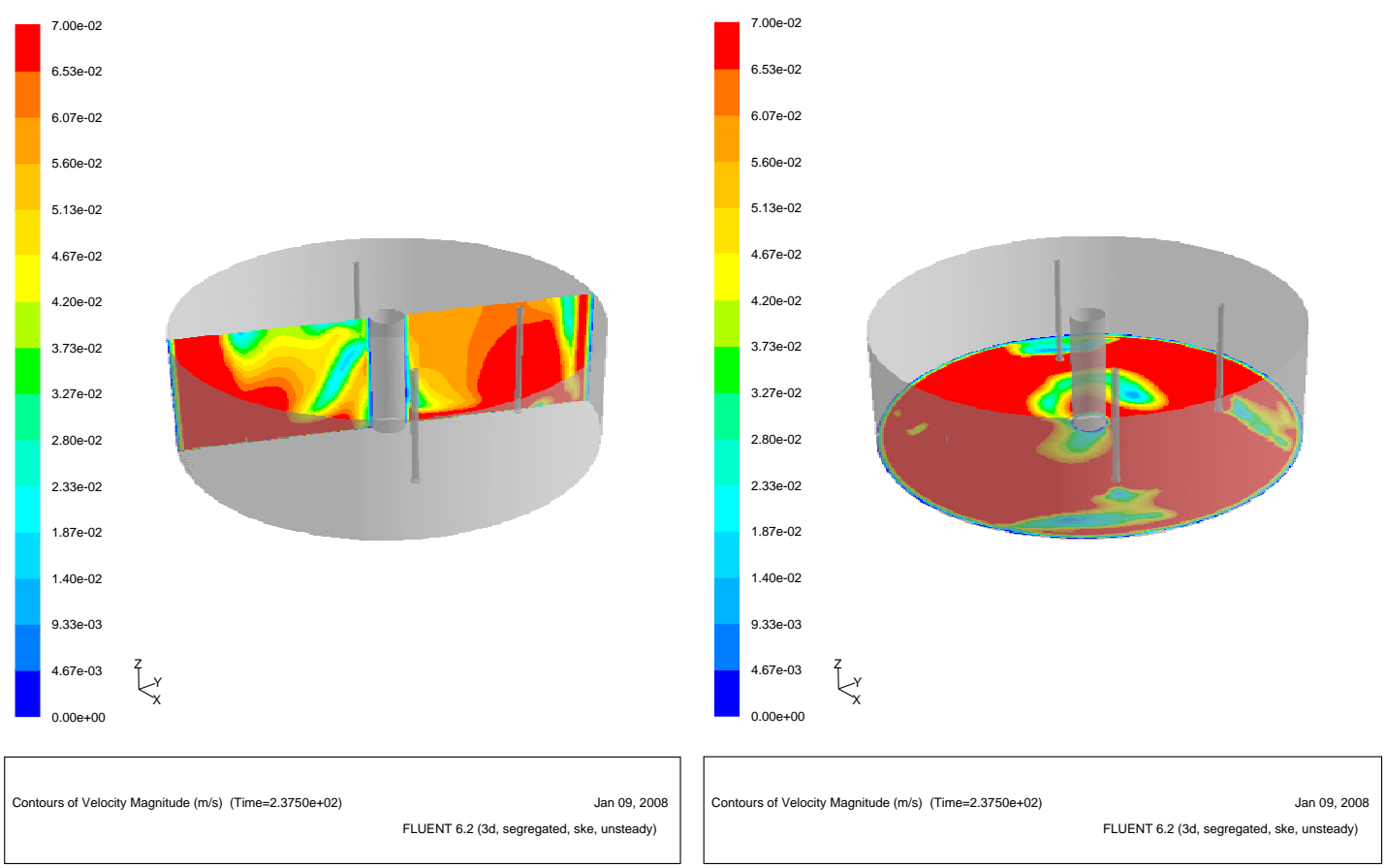

(Time $=240$ sec: location A in Fig. 6)

Figure 13. Velocity magnitude at the vertical and horizontal planes crossing the inlet region of the transfer pump TTP (Riser B5) at transient time 240 seconds, showing that red zone has local velocity magnitude higher than $0.07 \mathrm{~m} / \mathrm{sec}$ 

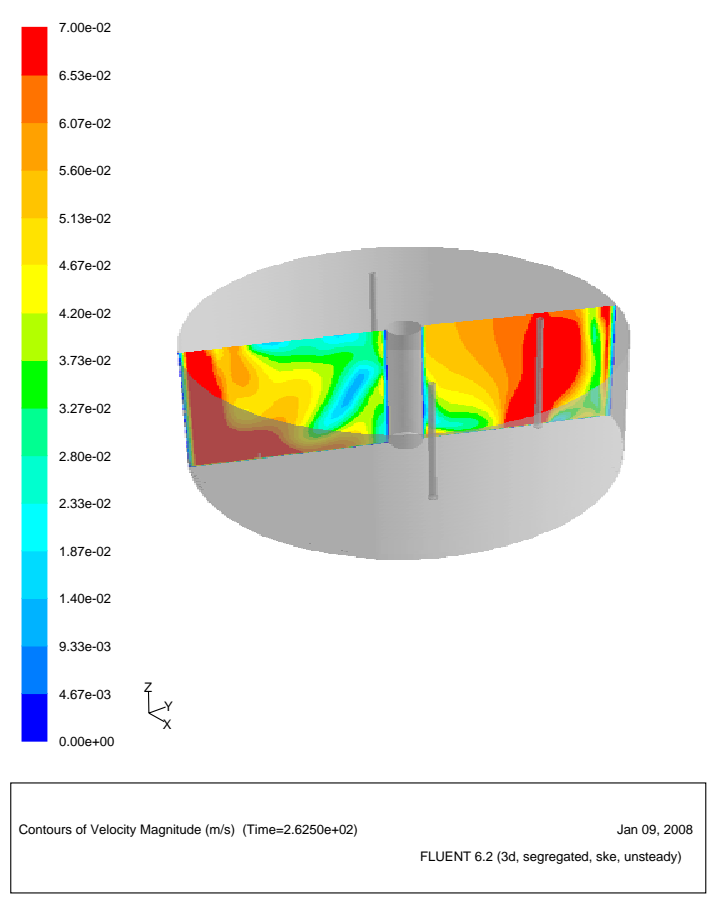
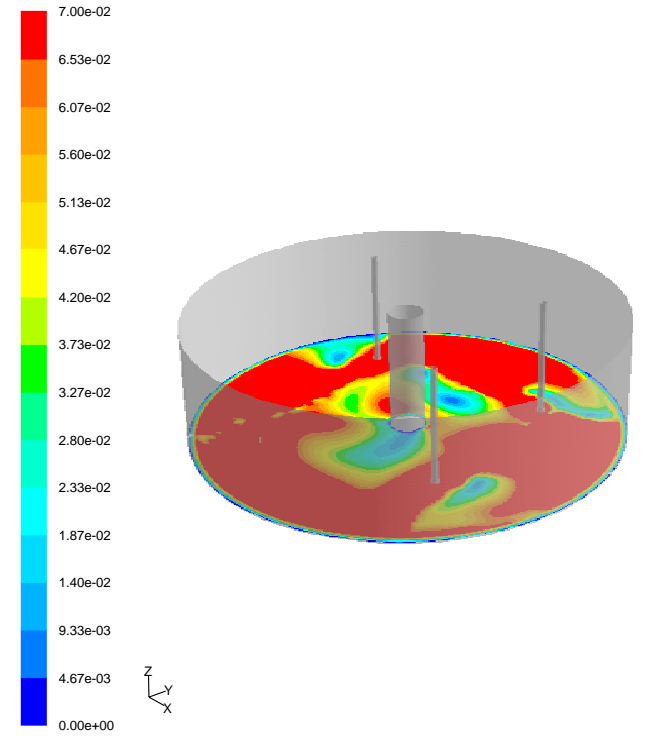

$x_{x}^{x}$

(Time = 275 sec: location B in Fig. 6)

Figure 14. Velocity magnitude at the vertical and horizontal planes crossing the inlet region of the transfer pump TTP (Riser B5) at transient time 275 seconds
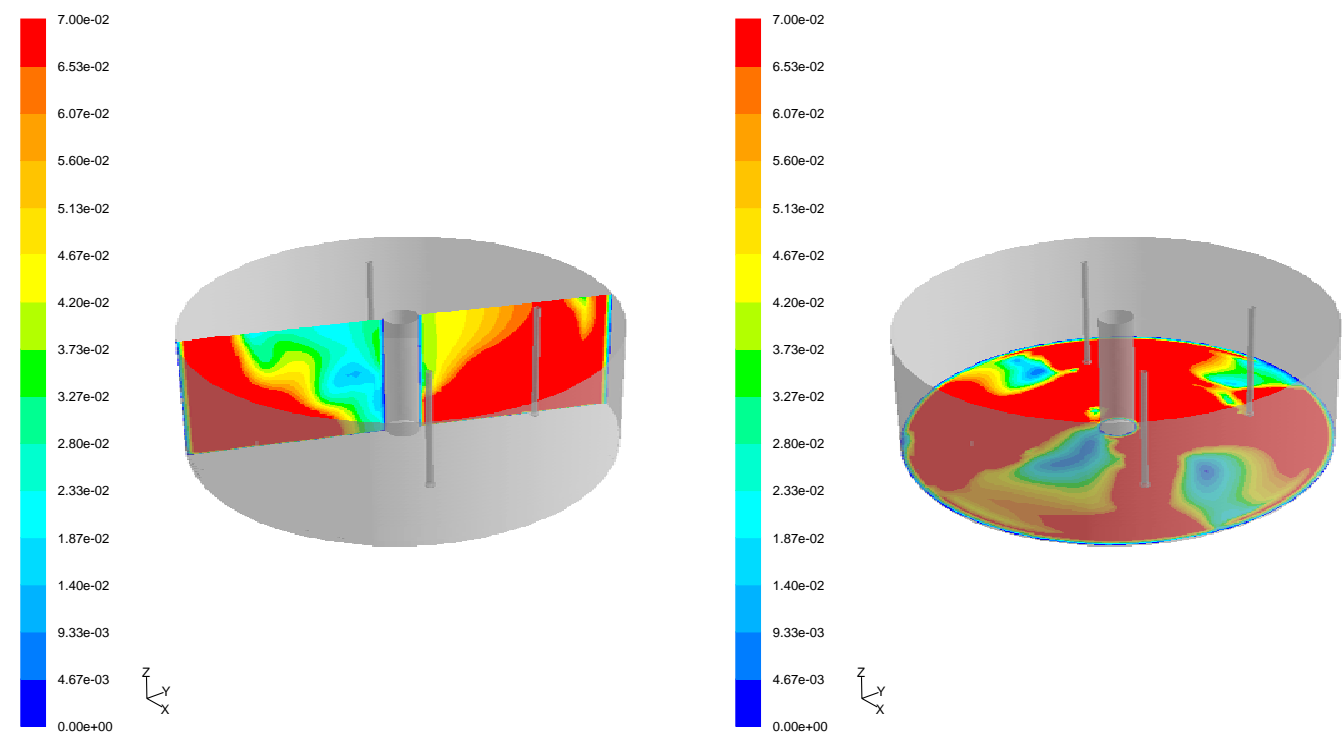

Contours of Velocity Magnitude (m/s) (Time $=3.0000 \mathrm{e}+02)$

Jan 09, 2008 FLUENT 6.2 (3d, segregated, ske, unsteady)

(Time $=300$ sec: location C in Fig. 6)

Figure 15. Velocity magnitude at the vertical and horizontal planes crossing the inlet region of the transfer pump TTP (Riser B5) at transient time 300 seconds showing that red zone has local velocity magnitude higher than $0.07 \mathrm{~m} / \mathrm{sec}$ 


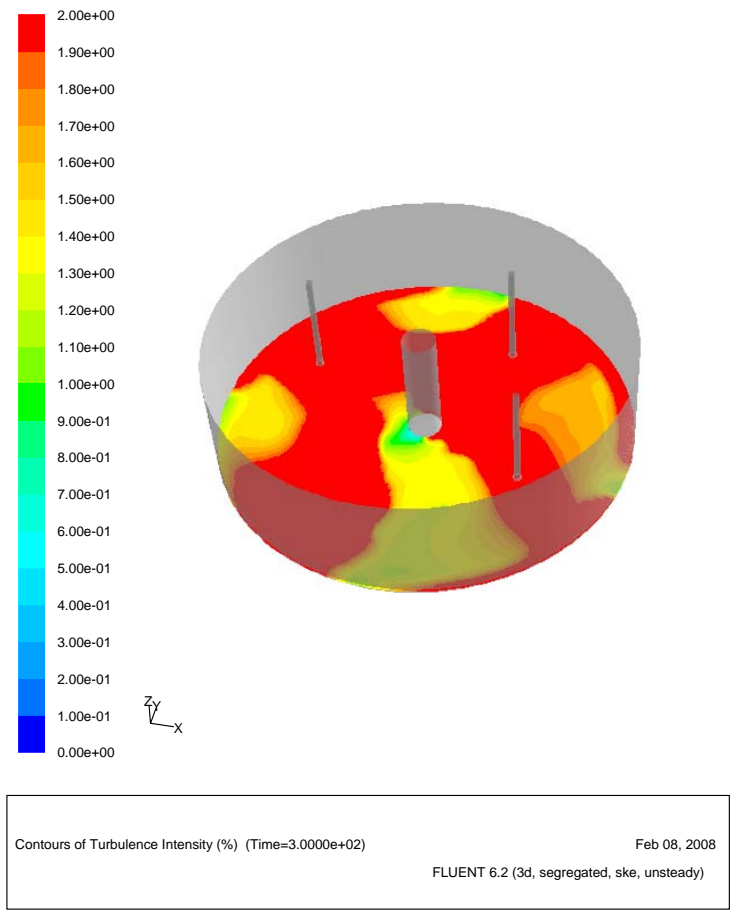

(Turbulent intensity: Red zone has local intensity higher than 2\%)
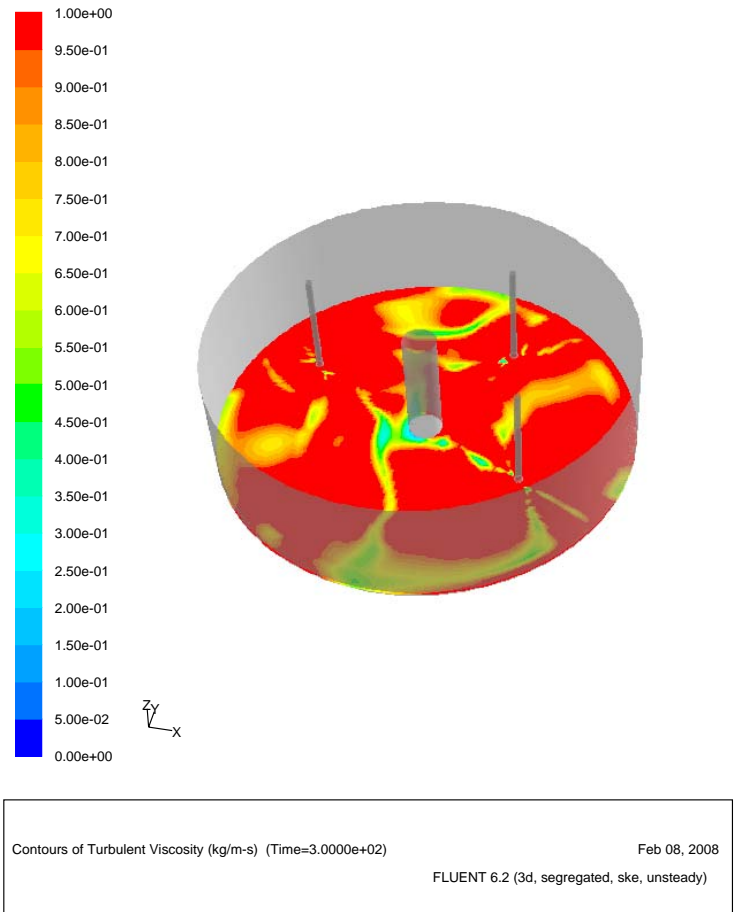

(Turbulent eddy viscosity: Red zone has local value higher than $1 \mathrm{~kg} / \mathrm{m}$-sec)

Figure 16. Transient snapshots of turbulent intensity and eddy viscosity at the horizontal plane crossing the inlet region of the transfer pump TTP (Riser B5) at transient time 300 seconds 


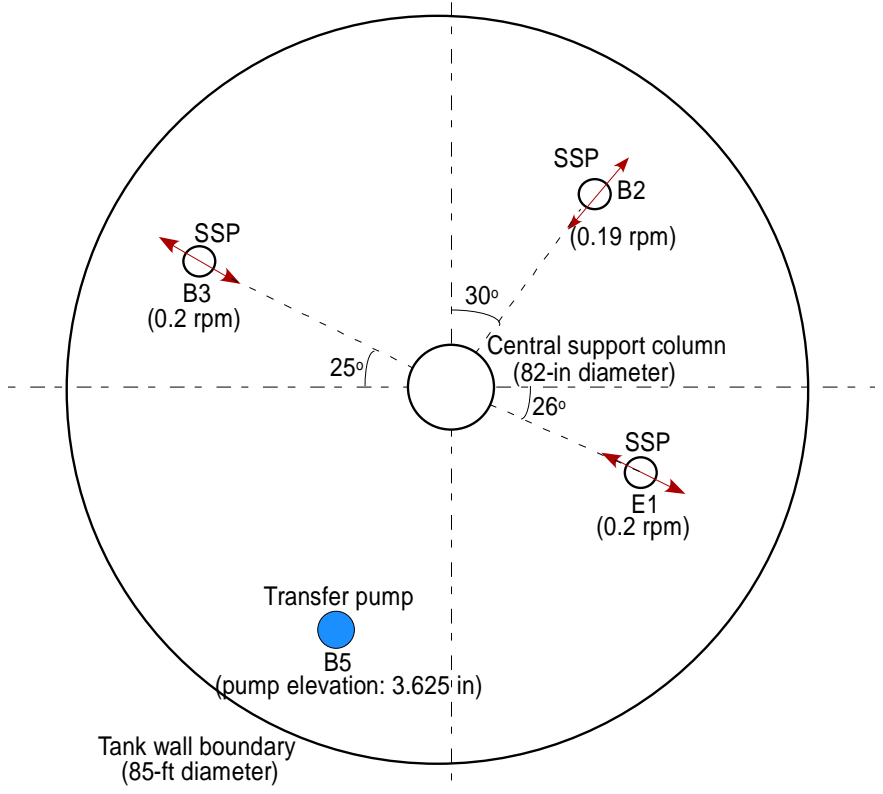

(Case-2b: Asynchronous pump rotation for B2 pump)

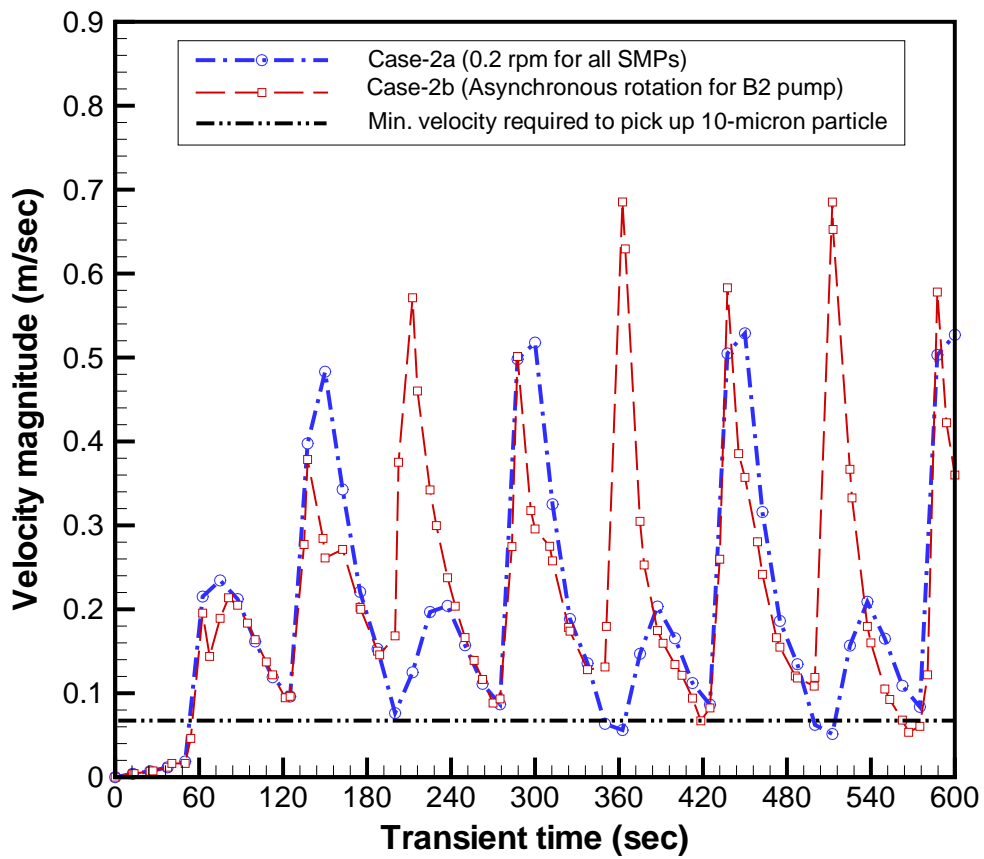

Figure 17. Comparison of transient velocity magnitude around the inlet region of TTP (Riser B5) between synchronous and asynchronous rotational speeds of B2 pump. 


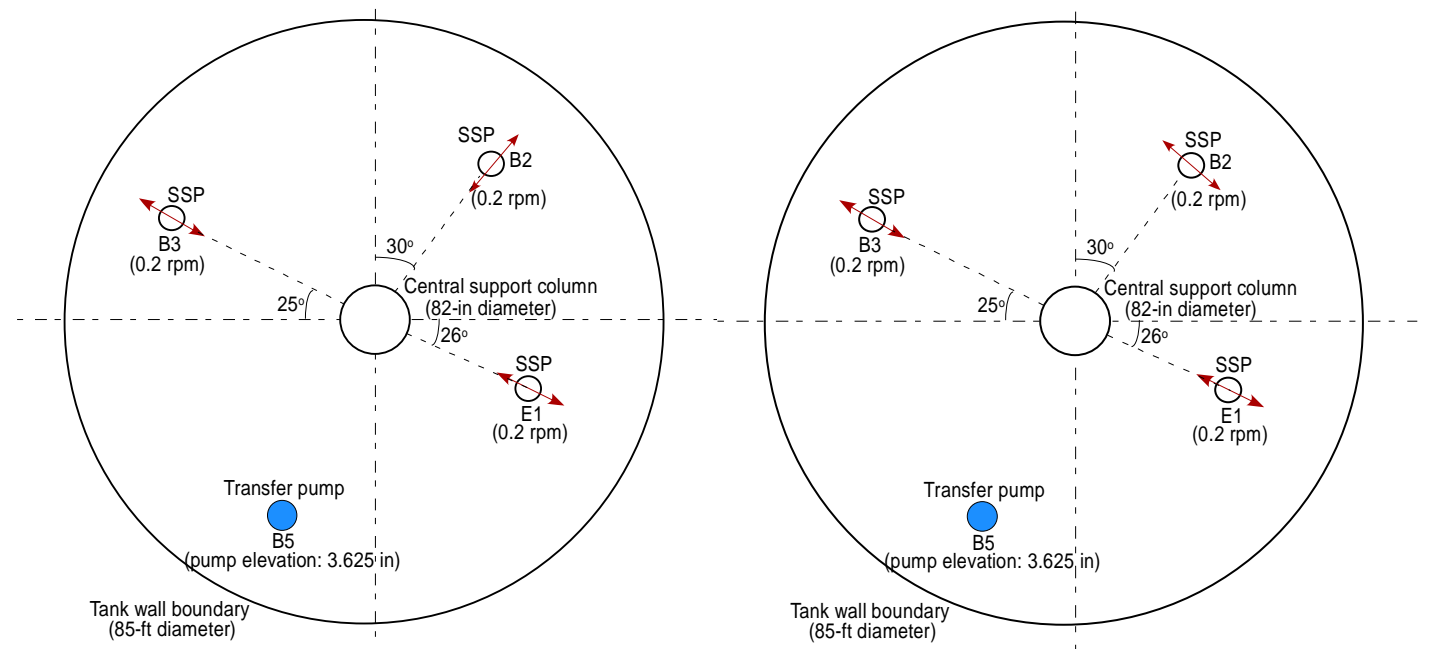

(Case-2a: Synchronous initial conditions)

(Case-2c: random initial conditions)

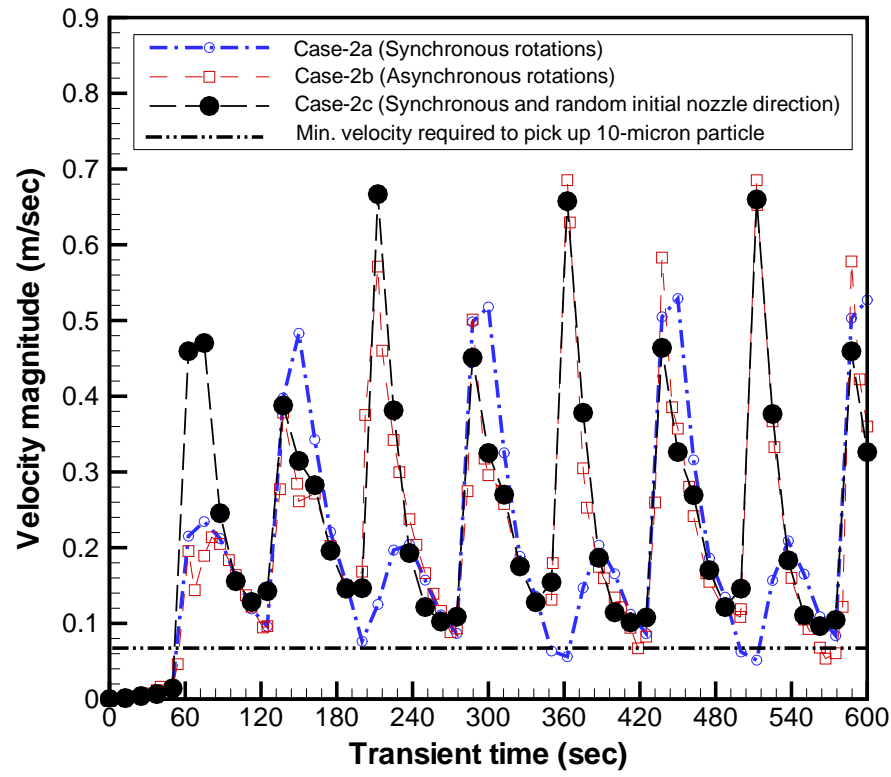

Figure 18. Comparison of transient velocity magnitudes around the inlet region of TTP (Riser B5) between asynchronous and random initial conditions of B2 pump. 


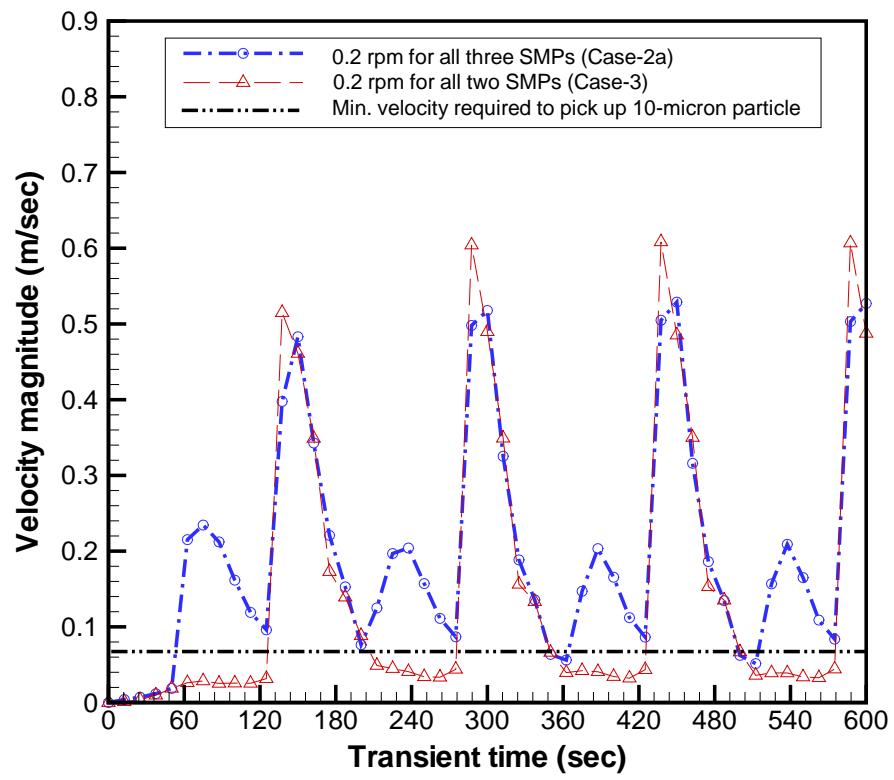

Figure 19. Comparison of transient velocity magnitudes around the inlet region of TTP (Riser B5) between the two different operating conditions of three SSPS (Case-2a) and two SSPs (Case-3).

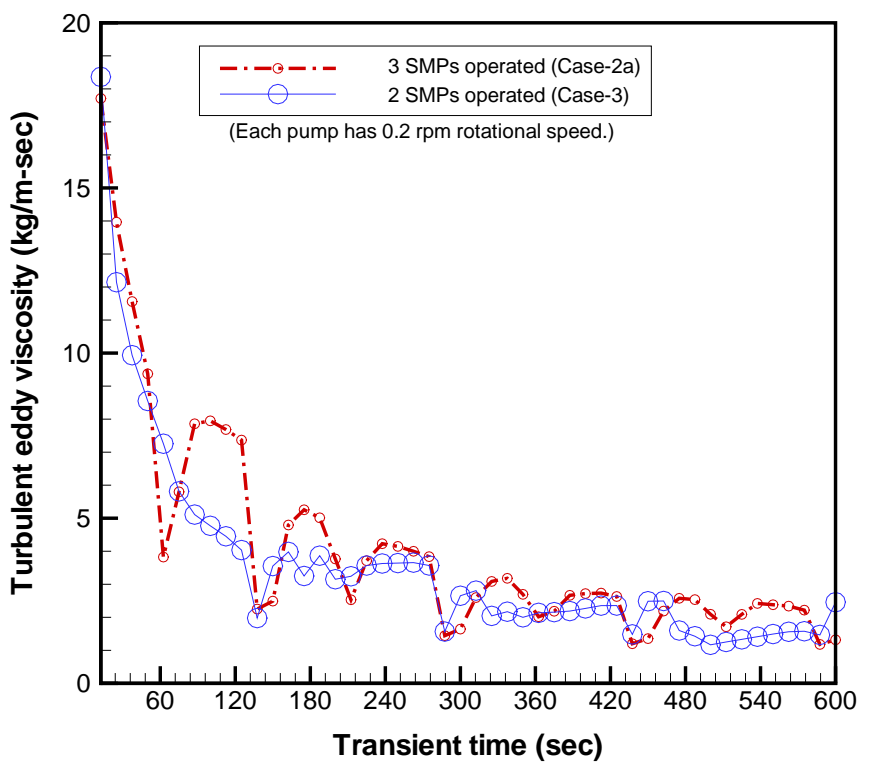

Figure 20. Comparison of transient turbulent eddies around the inlet region of TTP (Riser B5) between three and two SSPs operations 

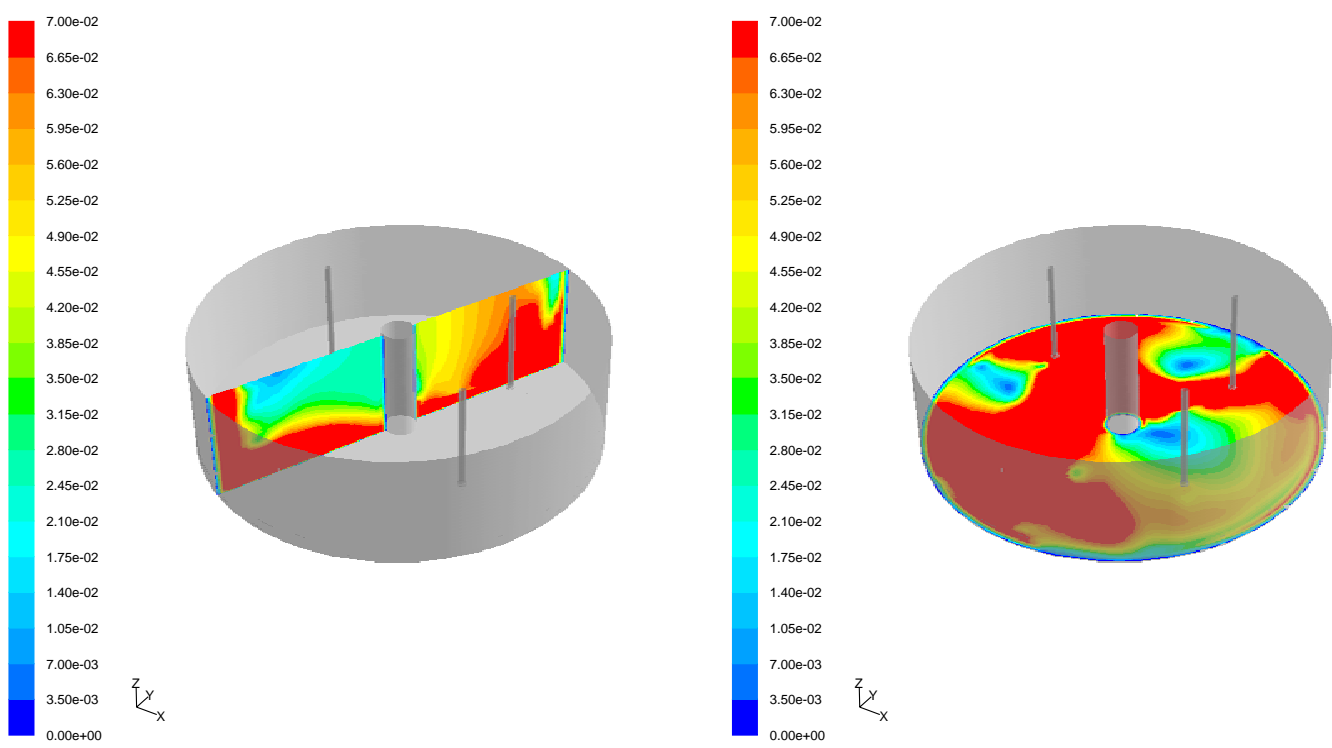

Contours of Velocity Magnitude $(\mathrm{m} / \mathrm{s})($ Time $=3.0000 \mathrm{e}+02)$

Feb 13, 2008

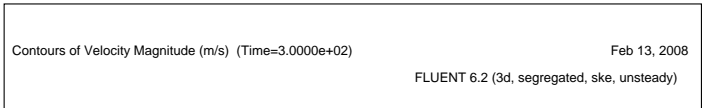

Figure 21. Velocity magnitude at the vertical and horizontal planes crossing the inlet region of the transfer pump TTP (Riser B5) at transient time 300 seconds under the Case-3 operating condition, showing that red zone has local velocity magnitude higher than $0.07 \mathrm{~m} / \mathrm{sec}$
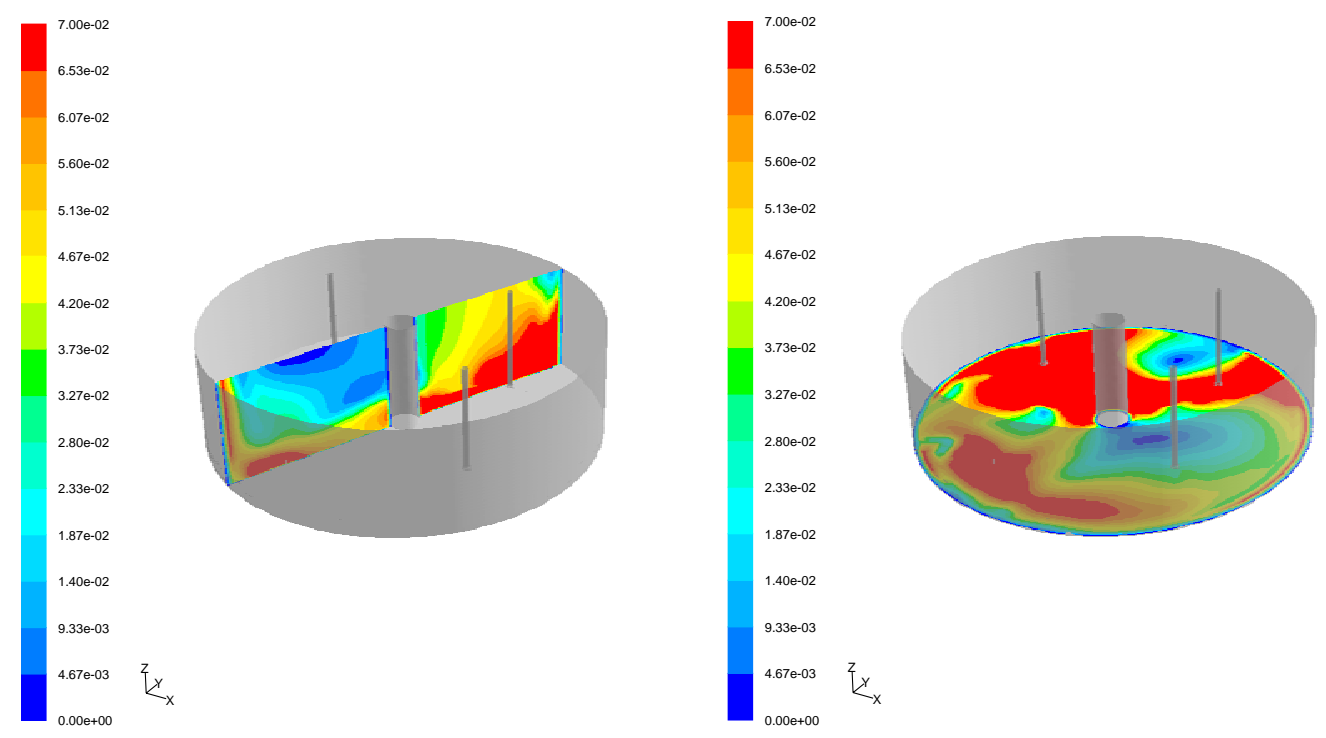

Contours of Velocity Magnitude (m/s) $($ Time $=3.0000 \mathrm{e}+02$

Feb 12, 200 FLUENT 6.2 (3d, segregated, ske, unsteady)

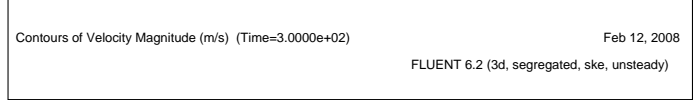

Figure 22. Velocity magnitude at the vertical and horizontal planes crossing the inlet region of the transfer pump TTP (Riser B5) at transient time 300 seconds under the Case-4 operating condition, showing that red zone has local velocity magnitude higher than $0.07 \mathrm{~m} / \mathrm{sec}$ 

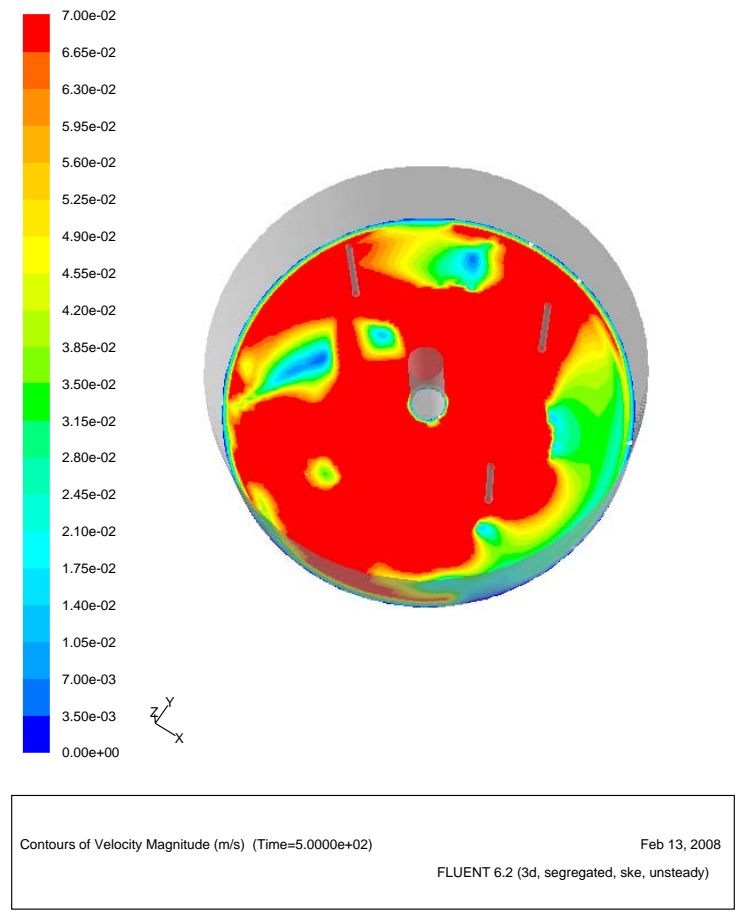

(Case-3)
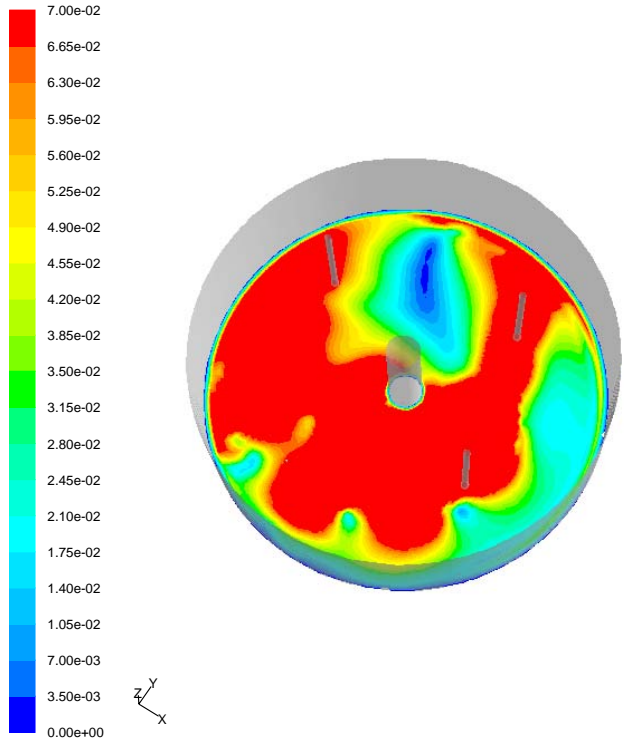

Contours of Velocity Magnitude (m/s) (Time $=5.0000 e+02$ Feb 13, 2008 FLUENT 6.2 (3d, segregated, ske, unsteady)

(Case-4)

Figure 23. Comparison of quasi-steady snapshots of flow velocity magnitudes at the horizontal plane crossing the inlet region of the transfer pump TTP (Riser B5) (Red zone has local value higher than $0.07 \mathrm{~m} / \mathrm{sec}$.) 


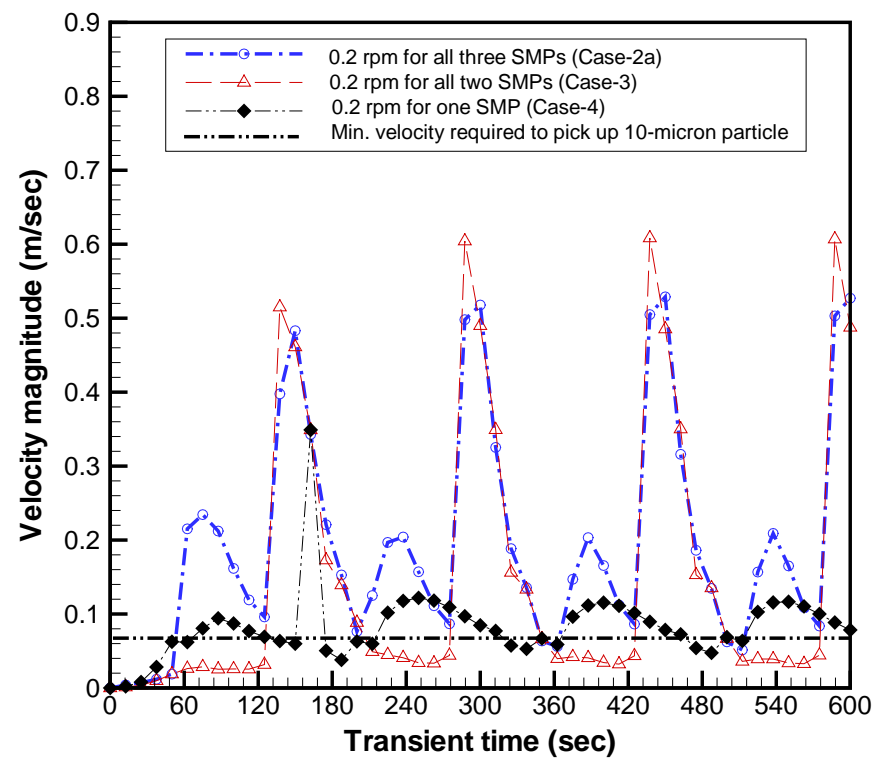

Figure 24. Comparison of transient velocity magnitudes at the inlet region of the transfer pump TTP (Riser B5) under various pump combinations as shown in Table 1 

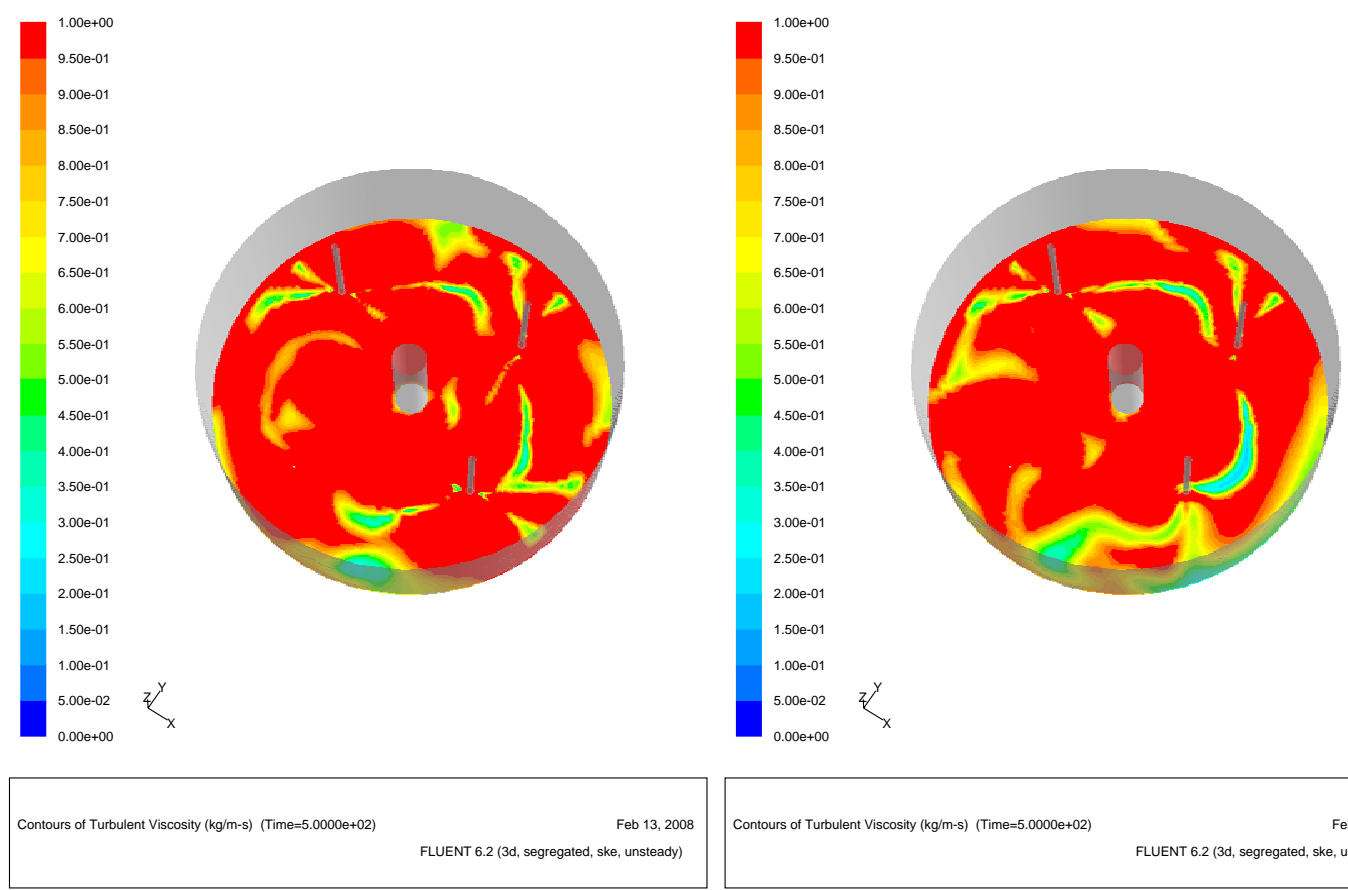

(Case-2a)

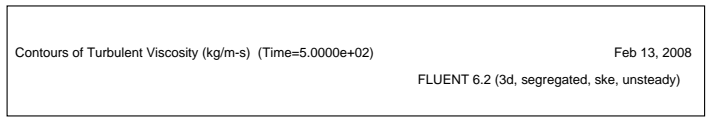

(Case-3)
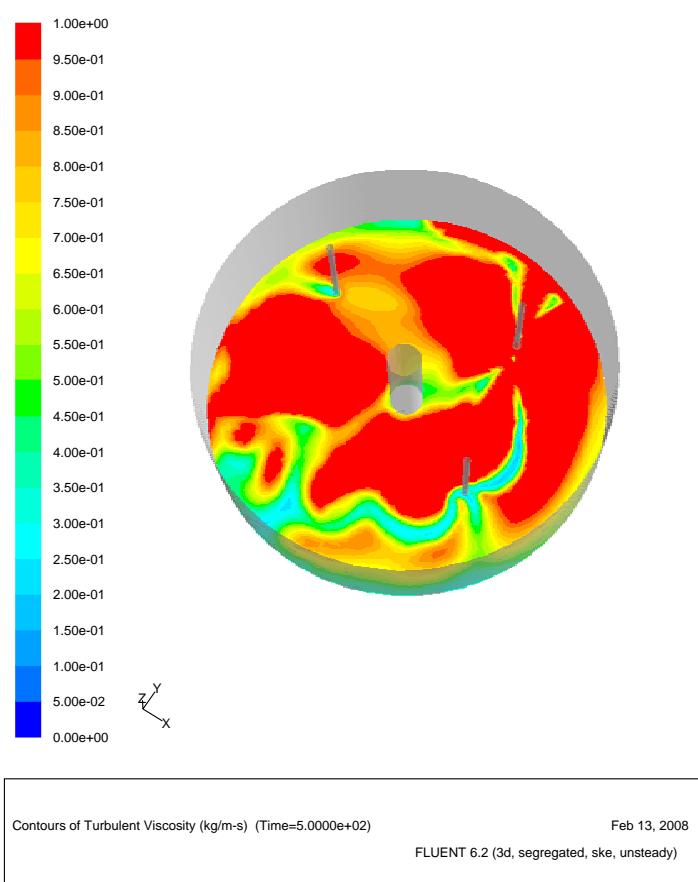

(Case-4)

Figure 25. Comparison of quasi-steady snapshots of turbulent eddy viscosity at the horizontal plane crossing the inlet region of the transfer pump TTP (Riser B5) (Red zone has local value higher than $1 \mathrm{~kg} / \mathrm{m}-\mathrm{sec}$.) 


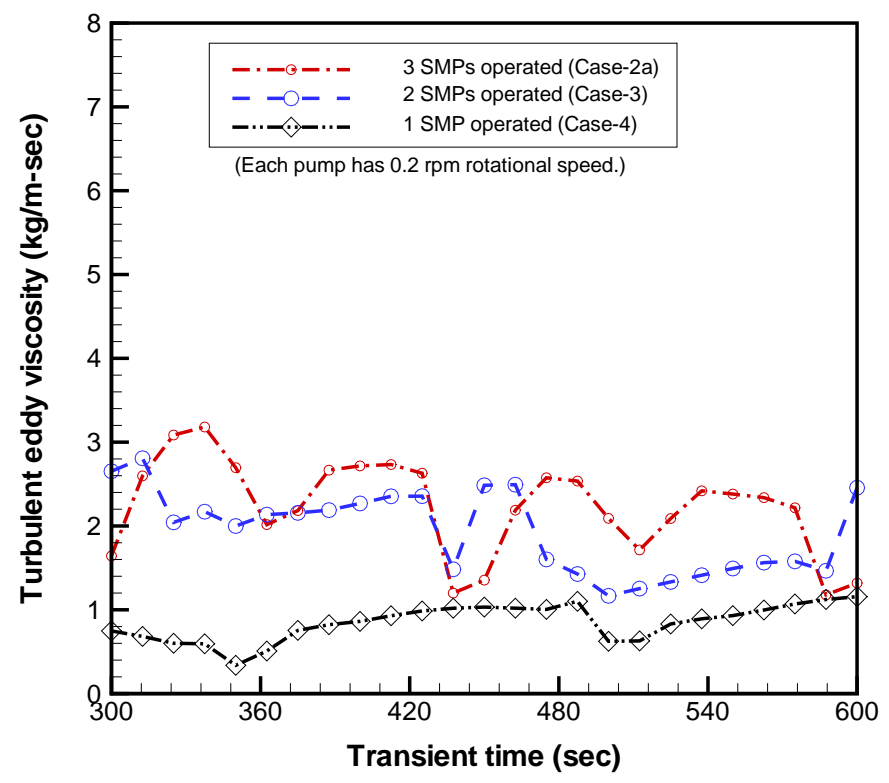

Figure 26. Comparison of quasi-steady turbulent eddy viscosities at the horizontal plane crossing the inlet region of the transfer pump TTP (Riser B5) under various pump combinations as shown in Table 1

Table 5. Summary of local flow velocity magnitude and flow mixing time to establish quasi-steady flow patterns under various cases

\begin{tabular}{|c|c|c|c|c|}
\hline Cases & $\begin{array}{l}\text { Local velocity } \\
\text { magnitude near } \\
\text { transfer pump inlet } \\
(\mathrm{m} / \mathrm{sec})\end{array}$ & $\begin{array}{l}\text { Local velocity } \\
\text { magnitude required } \\
\text { for 10-micron solids } \\
(\mathrm{m} / \mathrm{sec})\end{array}$ & $\begin{array}{l}\text { Time to reach } \\
\text { quasi-steady } \\
\text { turbulent eddies } \\
\text { (min.) }\end{array}$ & $\begin{array}{c}\text { Mixing time based } \\
\text { on literature } \\
\text { correlation [8] } \\
\text { (min.) }\end{array}$ \\
\hline $\begin{array}{l}\text { Case-2a, } \\
-2 b,-2 c \\
\text { (3 SSPs } \\
\text { operated) }\end{array}$ & $u_{\text {local }}>0.07$ & \multirow[t]{3}{*}{0.07} & About 6 minutes & \multirow{3}{*}{$\begin{array}{c}\text { About } 10 \text { miniutes } \\
\text { (based on single } \\
\text { pump) }\end{array}$} \\
\hline $\begin{array}{c}\text { Case-3 } \\
\text { (2 SSPs } \\
\text { operated) }\end{array}$ & $\begin{array}{c}\mathrm{u}_{\text {local }}<0.07 \text { for time } \\
\text { interval of about } 70 \\
\text { seconds }\end{array}$ & & About 7 minutes & \\
\hline Case-4 & $\begin{array}{c}\mathrm{u}_{\text {local }}<0.07 \text { for time } \\
\text { interval of about } 60 \\
\text { seconds* }^{*}\end{array}$ & & About 8 minutes & \\
\hline
\end{tabular}

Note: *About $19 \mathrm{~min}$. of minimum settling time required for complete settle-down 


\section{Summary and Conclusions}

A Tank 50 simulation model with three standard slurry pumps has been developed to estimate flow patterns for an efficient sludge mixing. Sensitivity calculations for different numbers of pumps and operational modes have been performed to provide operational guidance for sludge suspension and mixing in Tank 50. Reference pump design and operating conditions shown in Table 2 were used to perform the analysis of the tank sludge suspension. In the analysis, the pump was assumed to be rotating. Major solid obstructions including the pump housing, the pump columns, and the 82-in central support column were included.

Transient analyses with a two-equation turbulence model were performed with FLUENT $^{\mathrm{TM}}$, a commercial computational fluid dynamics (CFD) code. All analyses were based on three-dimensional results. Recommended operational guidance was developed assuming that local fluid velocity and turbulent eddy distribution can be used as a measure of sludge suspension and spatial mixing.

The main conclusions drawn from the Tank 50 modeling and calculations are as follows:

- Sludge mixing is established in about 6 minutes after the beginning of pump operations. This result compares well with correlations in the literature.

- The results show that three-pump operation of Case-2 will give acceptable homogeneous mixing in about 6 minutes in terms of flow patterns and turbulent energy dissipation.

- Two-pump operation of Case-3 provides a marginal level of sludge suspension and turbulent mixing, while one-pump operation of Case-4 does not provide acceptable flow patterns and turbulent eddies for good mixing.

- Single-pump operation provides the smallest eddies in far-field region of the pump jet.

The results of these mixing analyses must be considered qualitative, since we do not have definitive benchmarking criteria required for a quantitative evaluation. For a detailed quantitative analysis, the benchmarking tests of the mixing criteria against the onsite $[14,15]$ and offsite test results [8] are recommended. 


\section{References}

1. T. E. Britt, "CFD Modeling of Tank 50H", HLE-TTR-2008-21, December 2007.

2. Dwg.\#W706692, Savannah River Plant BLDG 241-51H, 1993.

3. S. Y. Lee, R. A. Dimenna, R. A. Leishear, and D. B. Stefanko, "Analysis of Turbulent Mixing Jets in a Large Scale Tank", ASME Journal of Fluids Engineering, vol. 130, No. 1, January 2008.

4. S. Y. Lee and R. A. Dimenna, "Performance analysis for Mixing Pumps in Tank 18", WSRC-TR-2001-00391, October 2001.

5. FLUENT, Fluent, Inc., 1998.

6. Abramovich, G. N., "The Theory of Turbulent Jets", The MIT Press, Cambridge, MA, 1963.

7. W. H. Graf, Hydraulics of Sediment Transport, McGraw-Hill Book Company (1971).

8. R. K. Greenville and J. N. Tilton, "A New Theory Improves the Correlation of Blend Time Data From Turbulent Jet Mixed Vessels", Inst. of Chemical Engineers, vol. 74, Part A., pp. 390-396, April 1996.

9. G. G. Stokes, "On the Effect of the Internal Friction of Fluids on the Motion Pendulums", Trans. Cam. Phil. Society, Vol. 9, pp. 8, 1851.

10. N. V. Chadrasekhara Swamy and P. Bandyopadhyay, "Mean and Turbulence Characteristics of Three-Dimensional Wall Jets", Journal of Fluid Mechanics, Vol. 71, Part 3, pp. 541-562 (1975).

11. D. R. Oliver, "The Sedimentation of Suspensions of Closely-Sized Spherical Particles", Chemical Engineering Science, Vol. 15, pp. 230-242, 1961.

12. Dallavalle, J. M., Micromeritics, $2^{\text {nd }}$ Edition, Pitman Publishing Corporation, New York, 1948.

13. Chemical Engineer's Handbook, edited by J. H. Perry, third edition, McGraw-Hill, New York, 1950.

14. E. K. Hansen, "Recommendations for Operation of the Salt Feed Tank Based on the Tank 50 Sample Pulled April 2007", SRNL-PSE-2007-00140, Rev. 0, June 7, 2007.

15. C. C. Herman and F. F. Fondeur, "Initial Results for SRNL Characterization and Settling Testing of Tank 51 - Sludge Batch 4", SRNL-ITS-2005-00272, December 2005. 